\title{
Dendrimers and Dendritic Polymers as Anti-infective Agents: New Antim- icrobial Strategies for Therapeutic Drugs
}

\author{
J. Rojo ${ }^{1, *}$ and R. Delgado ${ }^{2, *}$
}

${ }^{1}$ Laboratorio de Sistemas Glicodendriticos, Grupo Carbohidratos, Instituto de Investigaciones Químicas, CSIC, Sevilla, Spain; ${ }^{2}$ Laboratorio de Microbiología Molecular, Servicio de Microbiología, Hospital Universitario 12 de Octubre, Madrid, Spain

\begin{abstract}
Nearly 3 decades ago, a dendritic structure was stepwise synthesized for the first time as a new type of molecules with promising applications. During years a huge effort has been devoted to implement the synthetic skills concerning the synthesis of these molecules and especially, new methods for purification and characterization of these compounds that are in the nanoscale range. The chemical manipulation of the surface and inner core of dendrimers were strategically used to allow a tailor-made control of physical-chemical properties and to discover new applications in material science and biomedicine. Although several examples have been reported in the literature describing applications of functionalized dendrimers and acclaiming a key role of these molecules, very scarce examples are actually close to the market.

This review summarizes the state of the art of dendrimers and dendritic polymers as anti-infective agents, with a special focus on the strategies to block receptors used by pathogens for attachment, cell entry and dissemination. These nanometre size molecules are very attractive compounds as new drugs easily to be manipulated to improve their activity and scope. This is already a very active area of research, where we are involved, with interesting potential as demonstrated by the Phase I clinical trial of a functionalized dendrimer with real possibilities to reach the market soon. The success of this compound should provoke an enormous stimulus to scientists working in this area as well as in the industrial companies for investment in this topic.
\end{abstract}

\section{INTRODUCTION}

At the end of the 70's the first cascade molecule was synthesized and characterized as a new type of chemical structure [1]. These new hyperbranched structures which resemble the branches of a tree were named dendrimers from the greek word dendron (meaning tree). The properties of dendrimers are mainly governed by the functional groups presented at the surface of these structures. The possibility to manipulate and change the nature of these functional groups open the opportunity to create tailor-made structures with broad spectra of application in different areas such as material science, catalysis, biomedicine, etc. These tree architectures were developed during two decades and an intense work was devoted to describe new synthetic methodologies to achieve so complex structures. Many isolation and purification problems were faced together with a critical point that still nowadays is considered a big challenge, the characterization of this type of molecules. Several good reviews recently published summarize the advances in this field concerning dendrimer synthesis and the state of the art [2-5]. Also, there are several reviews concerning the biological applications of dendrimers [6-12]. The aim of this review

*Address correspondence to these authors at the ${ }^{1}$ Laboratorio de Sistemas Glicodendríticos, Grupo de Carbohidratos, Instituto de Investigaciones Químicas, CSIC, Isla de la Cartuja, Americo Vespucio 49, Seville 41092 Spain; Tel: +34 95 4489568; Fax: +34 95 4460565; E-mail: javier.rojo@iiq.csic.es and ${ }^{2}$ Laboratorio de Microbiología Molecular, Servicio de Microbiología, Hospital Universitario 12 de Octubre, Av. de Córdoba s/n, Madrid 28041 Spain; Tel: +34-91-3908428; Fax: +34-91-5652765; E-mail: rdelgado.hdoc@salud.madrid.org will be focus mainly on the applications of these types of structures as antimicrobial agents with special interest on those examples applied to in vitro and in vivo studies. This is one of the applications in the biomedical area that has attracted the interest of scientists working on these dendritic architectures, mainly dendrimers, dendronized and dendritic polymers, and related molecules. This review is divided into different sections based on the infective agents but not in dendrimer structures. The nature of these dendrimers is diverse although in most cases these structures are functionalized with carbohydrates (glycodendrimers). We will describe the basic characteristic of these dendrimers and overview the infection processes where dendrimers have been used as antimicrobial agents.

\section{IMMUNOLOGICAL RECOGNITION OF PATHO- GENS}

Innate immunity has experienced an enormous progress in the last few years with the discovery and characterization of several families of receptors whose principal function is the recognition of invading microorganisms as predicted by Janeway [13]. These molecules recognized highly conserved motives on the surface of pathogens (pathogen-associated molecular patterns, PAMPs), hence the name of "patternrecognition receptors" (PRRs). The role of these diverse molecules in immune response is also complex. Toll-like receptors (TLRs) participate in the detection of a wide spectrum of PAMPs, being bacterial LPS recognition by TLR-4 the most representative example [14]. TLRs trigger a cascade of signalling that elicit a number of responses and connect 
innate and adaptative immunity [14]. The intracellular family of NOD-like receptors (NLRs) also participates in pathogen recognition and regulation of immune response. An imbalance in the function of some members of NLRs has been recently related to important inflammatory illnesses such as Crohn disease [15]. Targeting TLRs and NLRs to regulate immune response is nowadays an area of intense research. Ctype lectin receptors (CLRs) is an additional family of PRRs mainly expressed or secreted by myeloid cells whose mission in immune response includes both recognition of pathogens and intercellular signalling between immune competent cells [16]. CLRs exhibit different structures and properties but all have a carbohydrate-recognition domain (CRD) with a distinct specificity (Table $\mathbf{1}$ ).

It is increasingly clear that some microorganisms subvert the functionality of these receptors to gain access to cells and tissues. It is this role facilitating attachment and entry of pathogens that makes CLRs an interesting target to design anti-infective strategies. DC-SIGN is a CLR in which these characteristics exemplify most clearly.

DC-SIGN (Dendritic-Cell-Specific ICAM-3 Grabbing Non integrin) was characterized by Geijtenbeek et al. while searching for a ligand in Dendritic cells (DCs) for ICAM-3 in T-lymphocytes [20,32]. The gene had been identified years before as a part of a screening for cellular products with affinity for gp120, the principal component of HIV envelope, using a placental expression library [33]. The coincidence in DC-SIGN of expression on DCs, HIV binding and participation in cellular immune cross talk elicited great interest. It was shown that DC-SIGN is not a true viral receptor but what was called a trans-receptor: HIV can bind to DCSIGN and take advantage of this interaction since the viral particle, that normally has a half life of a few hours, is internalized and can be presented to susceptible CD4+ Tlymphocytes days after without minimal loss of infectivity. Soon it was also shown that DC-SIGN was a receptor for other important pathogens such as Ebola virus [23], Mycobacterium tuberculosis [22] or Cytomegalovirus [21]. It has been demonstrated that DC-SIGN recognizes high-mannose $\mathrm{N}$-linked carbohydrates present in substantial amounts as part of the envelope glycoproteins of these microorganisms.
Within the glycosylation moiety, the CRD of DC-SIGN binds preferentially to the outer trimannose branch Man1-3 [Man1-6]Man [34]. The characterization of DC-SIGN in DCs, and its closely related homologue DC-SIGNR or LSIGN in certain subsets of endothelial cells from liver sinusoids and lymph nodes [35], along with the increasing number of pathogens recognized by the receptor has greatly stimulated research on the molecule and potential applications. However the precise role that DC-SIGN plays in these infections is not completely understood in part due to the lack of a suitable animal model since mice have multiple loci of the murine counterpart with somewhat different specificities [36]. The best proof of the biological relevance of DC-SIGN in immune response is demonstrated by the impact on infection of different genetic polymorphisms in DC-SIGN found in population studies. It has been shown that a polymorphism in the promoter region is strongly correlated with a severe form of Dengue fever [37] and different polymorphisms of the molecule appear to be also related to different clinical course in HIV infection [38-40]. However, the precise mechanisms that explain these different responses related to DC-SIGN forms remain to be elucidated in future studies along with the potential to use DC-SIGN as a target to prevent or treat infection.

Another interesting application based in the unique properties of DC-SIGN is the use of the molecule to deliver antigens for immunization to DCs. The natural properties of DCs in antigen uptake and presentation to $\mathrm{T}$ cells through MHC molecules could increase the response obtained with vaccine candidates in cancer and infectious diseases [41]. It has been demonstrated, both in vitro and in vivo, that antigens bound to DC-SIGN antibodies undergo uptake by DCs and are efficiently presented to T-lymphocytes thus inducing proliferative responses [42-44]. Dendrimers, as it will be shown below, are promising candidates to target this molecules either to block pathogen binding or to deliver antigens to particular cell subsets.

\section{BACTERIAL INFECTION}

Bacterial are common infective agents producing a wide variety of diseases. Bacteria are still an important cause of

Table 1. C-type Lectins and Specific Ligands: ManLAM, (Mannosylated Lipoarabinomannan). Le, (Lewis). GlcNAc, (Nacetylglucosamine). GalNAc, (N-acetylgalactosamine). HIV, (Human Immunodeficiency Virus). HCV, (Hepatitis C Virus). CMV, (Cytomegalovirus). SARS, (Severe Acute Respiratory Syndrome) [17]

\begin{tabular}{|c|c|c|}
\hline CLR & Carbohydrate recognition & Pathogen \\
\hline \hline MR (CD206) & Mannose & HIV, Mycobacteria, Fungi [18,19] \\
\hline DC-SIGN (CD209) & $\begin{array}{c}\text { Mannan, High mannose glycosylation, ManLAM, Fucose, } \\
\text { Le } \begin{array}{c}\mathrm{X}, \mathrm{Y}, \mathrm{B} \\
\text { Leishmania [20-25] }\end{array}\end{array}$ & $\begin{array}{c}\text { HIV, Ebola virus, HCV, CMV, Dengue virus, Mycobacteria, } \\
\text { Fungi [26] }\end{array}$ \\
\hline Dectin-1 & High mannose glycosylation & C. albicans [27] \\
\hline Dectin-2 & Mannose, GlcNAc, Fucose & HIV [28] \\
\hline Langerin (CD207) & GalNAc & Schistosoma, Ebola virus [29] \\
\hline hMGL & $?$ & Ebola virus, SARS virus [30,31] \\
\hline LSECtin & ? & \\
\hline
\end{tabular}


mortality in developed countries and the origin of massive epidemics that spread very easily among the population of developing countries due to the lack of adequate sanitary conditions. Additionally, some bacteria are responsible to produce highly potent toxins that can be considered as biological warfare. The search for therapeutic and prophylactic agents against these toxins is a topic of extreme importance [45].

The broad use and sometimes abuse of antibiotics has contributed to the appearance of bacterial resistance that has forced the biomedical researchers to look for new strategies to combat bacterial infections. One of the most attractive alternatives is the inhibition of bacterial attachment to target cells during the first stages of the infection using antiadhesive molecules. Bacteria adhesion is mediated by specific carbohydrate-protein interactions between lectin-like proteins at the surface of bacteria and glycoconjugates (glycoproteins and glycolipids) at the surface of target cells or viceversa. Blocking this interaction should inhibit the attachment of bacteria to the target cell surface and stop the infection. Although carbohydrate-protein interactions are weak (tipically with affinities at the milimolar range) the efficiency of this recognition process is achieved in nature due to the presence of multivalent interactions. Several approaches have been conceived to inhibit this recognition process, basically developing carbohydrate multivalent compounds such as glycodendrimers and glycodendritic polymers. In this section, we will review the design and synthesis of dendrimers (most of them, glycodendrimers) used as potential antibacterial drugs. The classification of so many different structures described in the bibliography will be done in this review based on the type of bacteria target.

\section{Bacteria Producing $\mathrm{AB}_{5}$ Toxins}

This is a very important group of Gram-negative bacteria which produce toxins causing thousands of deaths every year. These toxins present six subunits, one A subunit that is responsible of the infection and a homopentameric $\mathrm{B}$ subunits $\left(\mathrm{B}_{5}\right)$ that are required for the attachment of the toxin to the cell surface. Inhibition of the attachment of the subunits $B_{5}$ should be enough to stop the infection process. This B unit presents a carbohydrate recognition site that interacts with carbohydrates present at the cell surface in a multivalent way (five simultaneous interactions between $\mathrm{B}_{5}$ and cell surface carbohydrates).

\section{Cholera Toxin}

Cholera toxin is an $\mathrm{AB}_{5}$ protein secreted by Vibrio cholerae causing the disease cholera. This is an infectious intestinal disease characterized by severe diarrhea, and vomiting that if untreated may be life-threatening due to enormous loss of water and electrolytes. The B subunit is able to recognize and interact with ganglioside GM1 at the cell membrane forming a pore for subunit A that blocks GTPase activity of $\mathrm{G}$ protein and results in an increase of the synthesis of cAMP. In the intestine this leads to watery, electrolyte rich diarrhea as $\mathrm{Cl}^{-}$leaves the cells followed by $\mathrm{Na}^{+}$and water.

The Schengrund group has developed oligosaccharide functionalized dendrimers to inhibit the binding of the $\mathrm{B}_{5}$ subunit to cell surface GM1 [46,47]. The dendritic cores used were tetra $\left(1^{\text {st }}\right.$ generation) (1) and octa(propylene imine) $\left(2^{\text {nd }}\right.$ generation) (2) dendrimers and the $1^{\text {st }}$ generation of Startburst ${ }^{\mathrm{TM}}$ (PAMAM) (3) (Fig. 1).

These scaffolds were functionalized with the carbohydrate moiety of ganglioside GM1 (Gal $\beta 1-3$ GalNAc $\beta 1-4$ [NeuNAco2-3]Ga1 1 1-4Glc) (oligo-GM1) by reaction with a phenylisothiocyanate derivative of this oligo-GM1. The average number of sugars at the surfaces of dendrimers 1, 2 and 3 was 4, 7, and 6 respectively. The inhibition studies were performed using a ${ }^{125}$ I-labeled cholera toxin B subunit $\left({ }^{125} \mathrm{I}-\mathrm{CT}-\mathrm{B}\right)$ and GM1-coated wells [46]. The $\mathrm{IC}_{50}$ found were $3 \mathrm{nM}$ for octa(propylene imine), 7-8 $\mathrm{nM}$ for tetra(propylene imine) and Starburst ${ }^{\mathrm{TM}}, 45 \mathrm{nM}$ for GM1 and $10 \mu \mathrm{M}$ for oligo-GM1. These results represented a 250 fold increase of activity for multivalent systems in comparison with the monovalent natural oligosaccharide. Cellular experiments were performed using NCTC-2071 murine fibroblast expressing GM1 in a controlled way and $\left({ }^{125} \mathrm{I}-\mathrm{CT}-\mathrm{B}\right)$ to explore the physiological interest of these dendrimers [47]. Octa( propylene imine) produced a clear inhibition effect of the adherence of CT-B to cell expressing GM1 at the surface. In summary, the authors concluded that these types of oligosaccharide functionalized dendrimers could serve as effective ligands for pathogens that adhere to oligosaccharides present at the target cell surface.

Pieters et al., have prepared dendrimers with a significant rigid backbone using 3,5-bis(2-aminoethoxy)benzoic acid as repeating unit [48]. Dendrimers of first G1 (4), second G2 (5), and third G3 (6) generations presenting 2, 4, and 8 lactose as sugars (R1 in Fig. 2) were prepared and characterized (Fig. 2).

The affinity of these compounds for cholera toxin B subunit was measured using fluorescence spectroscopy. CTB present a tryptophan (Trp 88) at the carbohydrate binding site which fluorescence is quenched by bound ligand. In these studies, apparent $K_{D}$ of $235 \mu \mathrm{M}, 99 \mu \mathrm{M}$, and $33 \mu \mathrm{M}$ were found for divalent (4), tetravalent (5), and octavalent (6) compounds respectively. The monovalent lactose gave a $K_{D}$ of $18 \mathrm{mM}, 545$ fold less potent than the octavalent dendrimer. In this study was also pointed out the importance of the size and shape of the spacer used to attach the carbohydrate moiety to the dendritic core.

Bernardi and Pieters groups have prepared a dendrimer using the same dendritic core described above functionalized with a GM1 mimic (R2 in figure 2) [49]. This system was tested for CTB binding using two techniques, SPR analysis and ELISA assays. The SPR gold chip was functionalized with a glycoprotein which carbohydrate moieties are good ligand for CTB. In these studies were found the following inhibition activities: lactose an $\mathrm{IC}_{50}$ of $9.4 \mathrm{mM}$, monovalent GM1 mimic an $\mathrm{IC}_{50}$ of $97 \mu \mathrm{M}$, the divalent compound (4, $\mathrm{R} 2)$ an $\mathrm{IC}_{50}$ of $13 \mu \mathrm{M}$ (17-fold enhanced respect to the monovalent), the tetravalent compound $(5, \mathrm{R} 2)$ an $\mathrm{IC}_{50}$ of $0.5 \mu \mathrm{M}$ (111-fold increased) and the octavalent compound (6, R2) an $\mathrm{IC}_{50}$ of $0.5 \mu \mathrm{M}$. The higher relative potency (per sugar) of the tetravalent system in comparison with the octavalent one was explained due to this compound reached the limit of the assay. A different assay based on ELISA was performed with the aim to evaluate the activity of this octavalent compound. The ELISA wells were coated with the ganglioside 


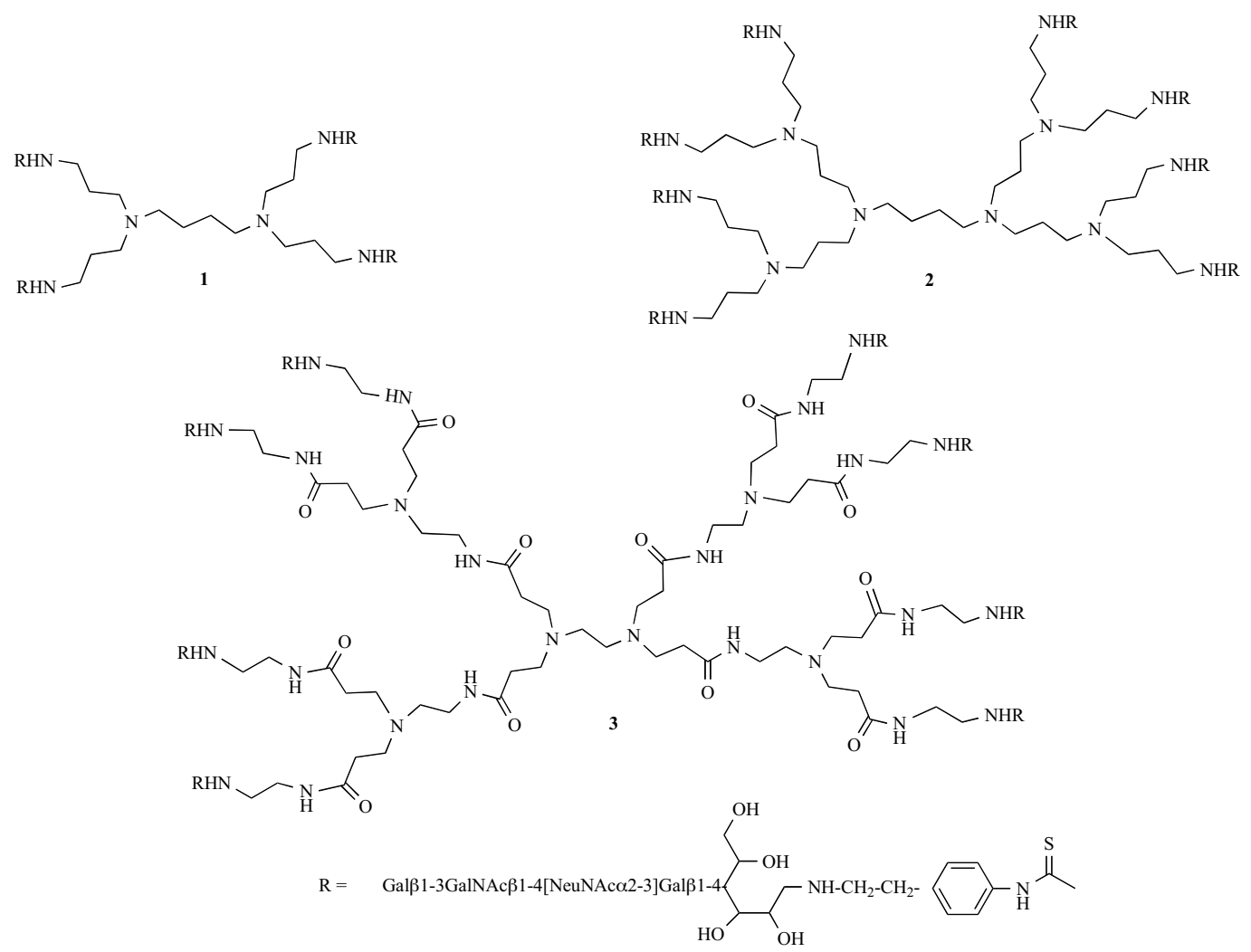

Fig. (1). Chemical structures of poly(propylene imine) (PPI) G1 (1) and G2 (2); and dendrimer PAMAM G1 (3) functionalized with carbohydrate moiety of ganglioside GM1.

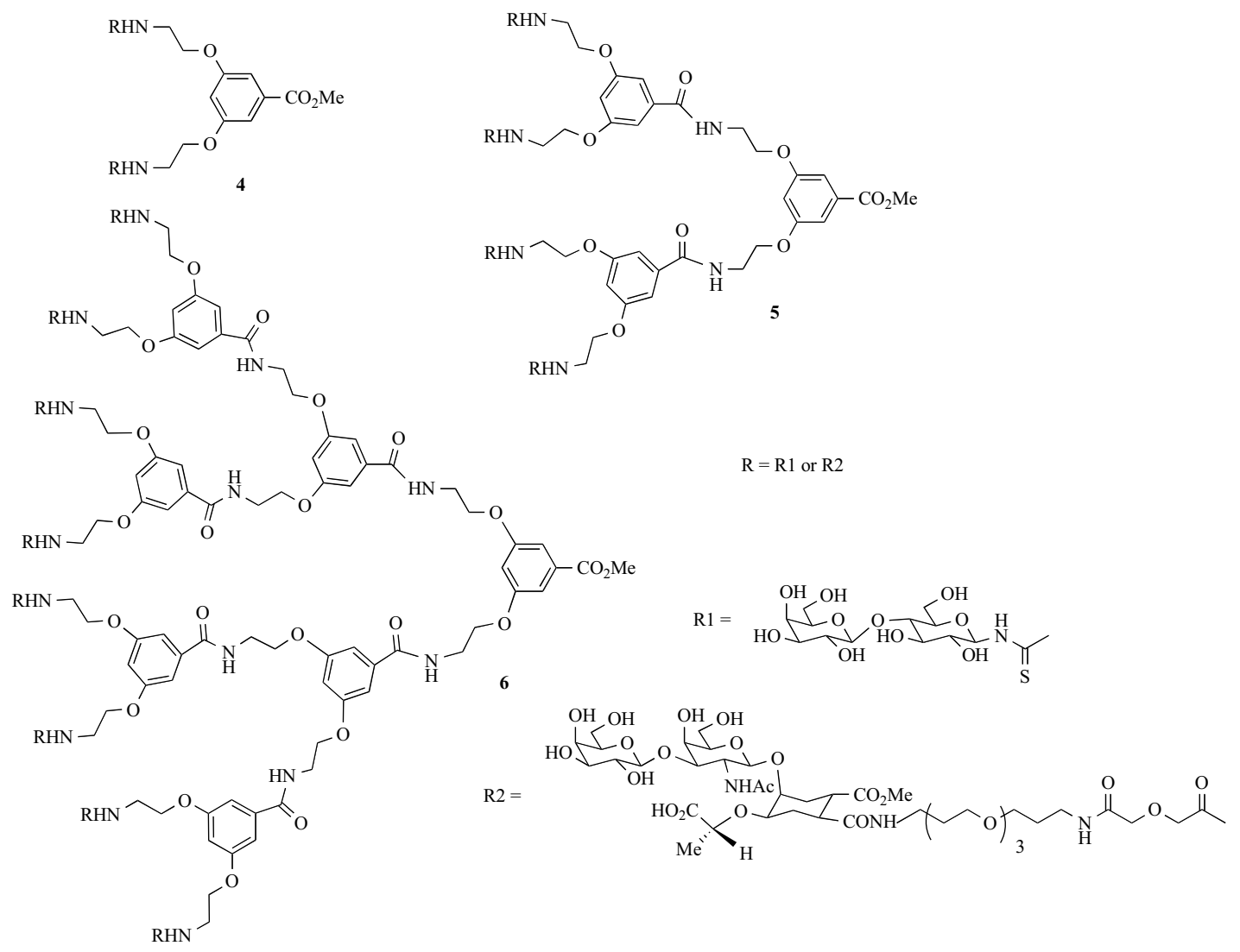

Fig. (2). Dendritic structures of G1 (4), G2 (5), and G3 (6) generation based on 3,5-bis(2-aminoethoxy)benzoic acid functionalized with lactose (R1) and Lewis X mimic (R2). 
GM1 and a CTB-horseradish peroxidase conjugate was used as binding protein. Only this octavalent system presented some inhibitory activity in these assays $(20 \%$ of inhibition at $400 \mu \mathrm{M}$ concentration of compound). These results demonstrated the high-affinity of this GM1 mimic ligand on a multivalent scaffold for this $\mathrm{AB}_{5}$ toxin. Also, it was demonstrated that the design of multivalent scaffolds for this toxins are not as important as the right design of the ligand.

\section{Shiga and Vero Toxins}

Shiga toxins (Stx1 and Sxt2), produced by Shigella dysenteriae and Shiga-like toxins (SLT-I and SLT-II) also called Vero toxins produced by Escherichia coli O157:H7, are $\mathrm{AB}_{5}$ toxins causing watery diarrhea or hemorrhagic coli- tis respectively that are particularly severe in children and elder people being responsible of millions of episodes around the world.

One of the more remarkable example in the rational design of multivalent systems for the inhibition of SLTs was described by Bundle et al., in a leading article few years ago [50]. Although it can not be considered as a dendrimer strictly speaking, the carbohydrate multivalent systems named STARFISH designed by Bundle et al., will be discussed here. The oligosaccharide receptor for shiga-like toxin on mammalian cells is the Gb3 glycolipid (Gal 1 $4 \mathrm{Gal} \beta 1-4 \mathrm{Glc} \beta 1-\mathrm{OCer})$. The corresponding trisaccharide was used as ligand to create a multivalent system presenting 10 carbohydrate units (Fig. 3).

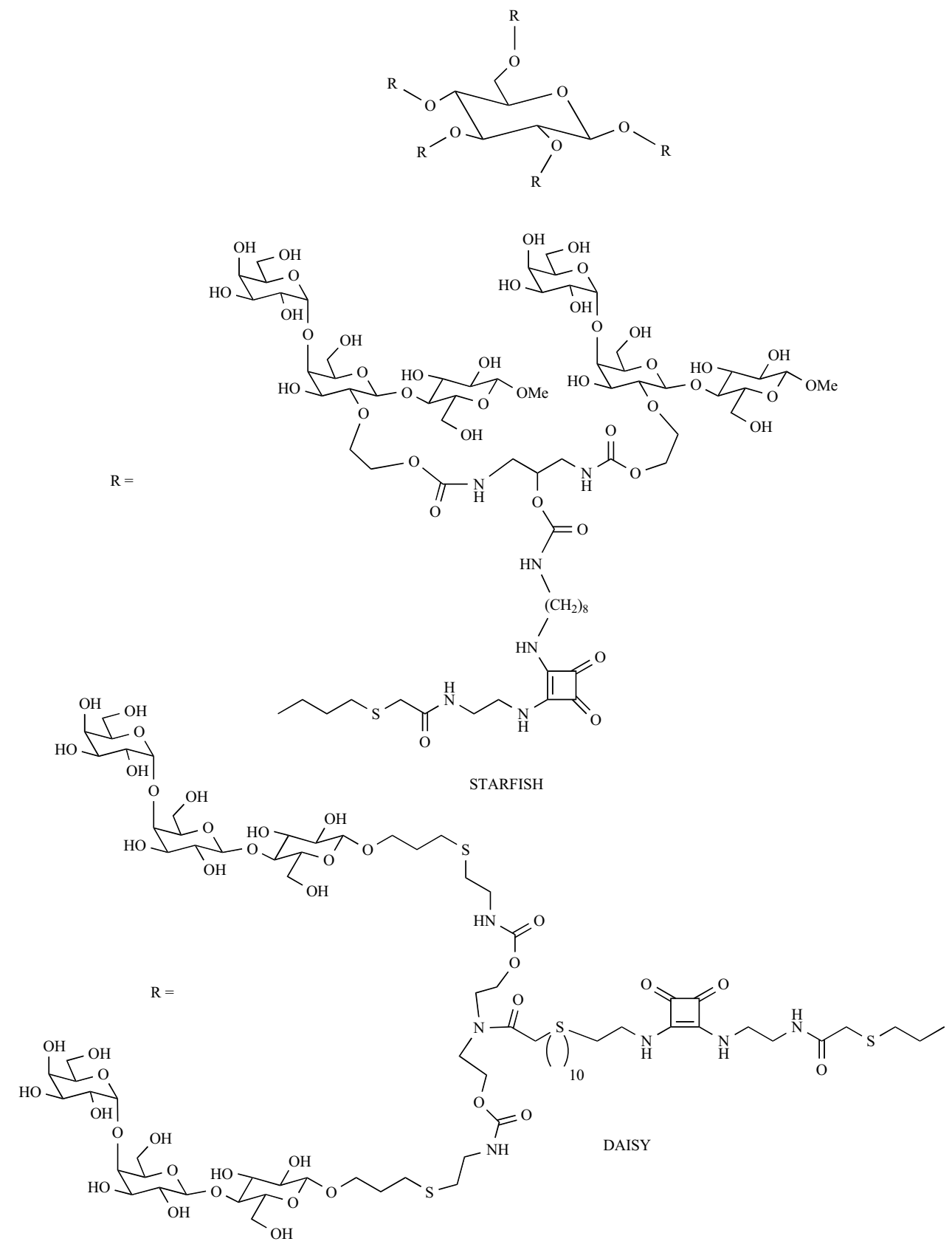

Fig. (3). Chemical structure of STARFISH and DAISY multivalent systems functionalized with globotriaose. 
In an ELISA assay, using 96-well plates coated with the trisaccharide and SLT-I and SLT-II in the presence or absence of inhibitors, were found for the STARFISH compound $\mathrm{IC}_{50}=0.4 \mathrm{nM}(\mathrm{STL}-\mathrm{I})$ and $\mathrm{IC}_{50}=6 \mathrm{nM}(\mathrm{STL}-\mathrm{II})$, a million-fold increase in comparison with the corresponding monovalent ligand. A crystal structure was obtained revealing the mode of binding of this STARFISH molecule. A 2:1 (Shiga toxin-STARFISH) sandwich complex was observed as a thermodynamically more stable complex. The findings of this work confirmed the potential use of multivalent carbohydrate systems as bacterial anti-adhesive therapeutics. Some years later, the therapeutically activity of STARFISH molecule was tested in mice using both Stx1 and Stx2 [51]. This molecule was able to protect mice inoculated subcutaneously with a lethal dose of Stx 1 with a $90 \%$ survival rate (inhibitor/toxin molar ratio of $10^{3}: 1$ ) and with $100 \%$ survival rate (inhibitor/toxin molar ratio of $10^{4}: 1$ ). However, this compound was not effective in protecting mice inoculated with Stx2. A modified version of STARFISH named DAISY whose major difference is the attachment of the sugar moiety to the multivalent scaffold through the anomeric position of the reducing end instead of position 2 of central galactose, was also tested (Fig. 3). DAISY was able to protect mice at $100 \%$ from both Stx 1 and Stx 2 in the toxin coadministration at molar ratios $2 \times 10^{3}: 1$ and $10^{5}: 1$ respectively. Subcutaneous injection of DAISY would create subcutaneous depot and would deliver the drug to reach target organs of Stx in a period of time sufficient to be therapeutically efficient but this was not confirmed. However, the authors indicated that a continuous intravenous infection in humans could be the most adequate way for a treatment (the clearance of DAISY from circulation via galactose-specific receptors in liver could be a problem to reach effective concentration in blood with a single dose). These very promising results will stimulate the search for new drugs based on carbohydrate multivalent systems as anti-adhesive compounds.

Using carbosilane dendrimers functionalized with the same Gb3 trisaccharide, Nishikawa et al., have studied the inhibition of infection by shiga toxin-producing $E$. coli 0157:H7 [52]. These dendritic structures named SUPER TWIG are constituted by a core of silicon-carbon bonds that are biologically inert. SUPER TWIGs (0)3, (1)6, and (1) 12 containing 3,6 , and 12 trisaccharides respectively were prepared (Fig. 4).

The $\mathrm{IC}_{50}(\mu \mathrm{g} / \mathrm{mL})$ found in the inhibition of binding experiments in vitro of Stx 1 and Stx2 to Vero cells are summarized in the Table 2. SUPER TWIGs (1)6, and (1)12 were able to inhibit the cytotoxicity of Stx1 and Stx2 towards Vero cells but not SUPER TWIGs (0)3.

In vivo studies in mice were performed inoculating intravenously a lethal dose of Stx2. Surprisingly, SUPER TWIG (1)6 was able to suppress the effects of Stx in a concentration of $5 \mu \mathrm{g} / \mathrm{g}$ of body weigh but mice treated with SUPER TWIG (1)12 did not survive more than 7 days. Apparently, other factor than the pure inhibition of adhesion (as observed in vitro) had to play an important role in the infection process in vivo. SUPER TWIG (1)6 was also able to protect mice from an oral infection with E. coli O157:H7. Analysis of the in vivo and in vitro results provided significant evidences to propose a dual mechanism of action in vivo of SUPER
TWIG (1)6 based on a) inhibition of the Stx adhesion to the target cell expressing globotrioside glycolipid, and b) induction of Stx uptake by macrophage. These preliminary results were performed with a first series of carbosilane dendrimers. Modifications of dendrimer structures concerning the number of carbohydrates at the surface of the dendrimers and the core structure were carried out by this group with the aim to optimize the inhibition activities [53,54].

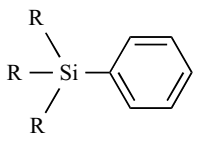

SUPER TWIG (0)3

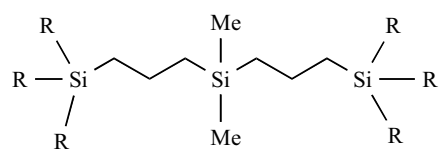

SUPER TWIG (1)6
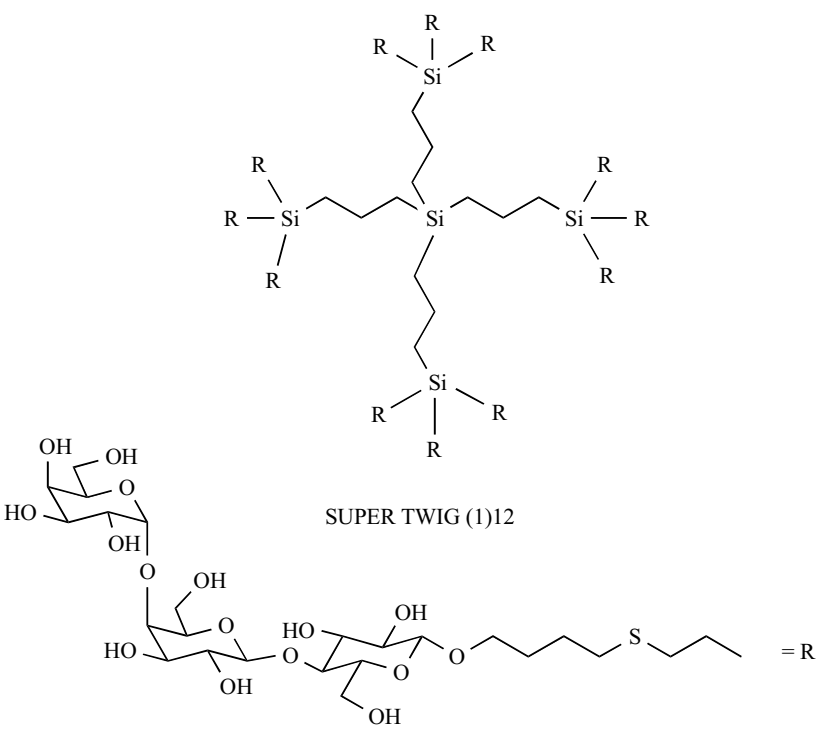

Fig. (4). Chemical structure of dendrimers SUPER TWIG (0)3, (1)6, and 1(12) functionalized with globotriaose.

Table 2. Inhibition $\left(\mathrm{IC}_{50}(\mu \mathrm{g} / \mathrm{mL})\right.$ of Binding Experiments Using Stx1, Stx2 and Carbosilane Dendrimer SUPER TWIGS

\begin{tabular}{|c|c|c|}
\hline Dendrimer & Stx1 & Stx2 \\
\hline \hline SUPER TWIG $(0) 3$ & $>40$ & $>100$ \\
\hline SUPER TWIG (1)6 & 0.22 & 2.3 \\
\hline SUPER TWIG (1)12 & 0.16 & 1.3 \\
\hline
\end{tabular}

Several new structures derived from SUPER TWIGs described before were designed and synthesized with the aim to improve the optimal function in circulation against shiga toxin (Fig. 5) [53].

Structures from 0 to 2 generation presenting up to 36 carbohydrates were prepared and tested. A kinetic analysis of binding of Stx 1 and Stx2 to these structures was carried out using biosensors. The $K_{D}$ values found for SUPER TWIGs with $4,6,9,12,18$, and 36 trisaccharides with respect to both Stxs were very similar. The inhibition activity of these dendrimers for the adhesion of ${ }^{125}$ I-labeled Stx to Vero cells was measured. The $\mathrm{IC}_{50}$ found for SUPER TWIGs (1)4, (1)9, (2) 18 , and (2)36 with $4,9,18$, and 36 carbohydrates respec- 


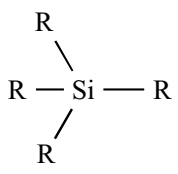

SUPER TWIG (0)4<smiles>[R][Si]([R])(C)CCC[Si]([R])(C)CCC[Si]([R])([R])C</smiles>

SUPERTWIG (1)4
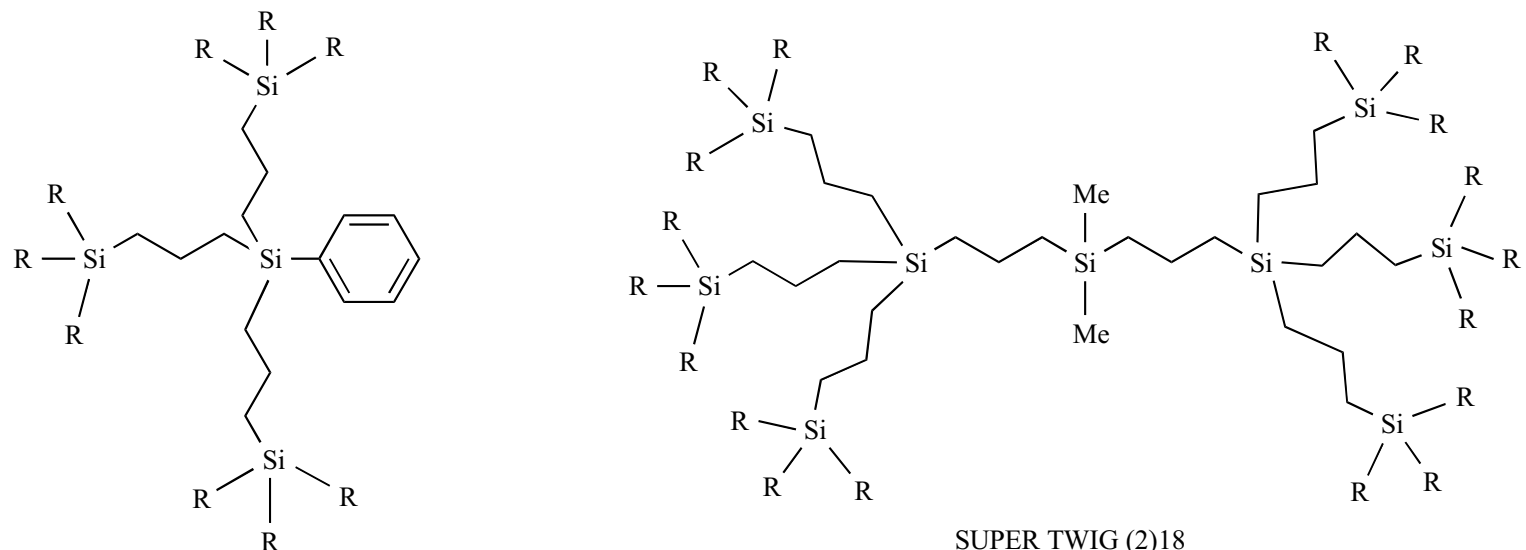

SUPER TWIG (1)9
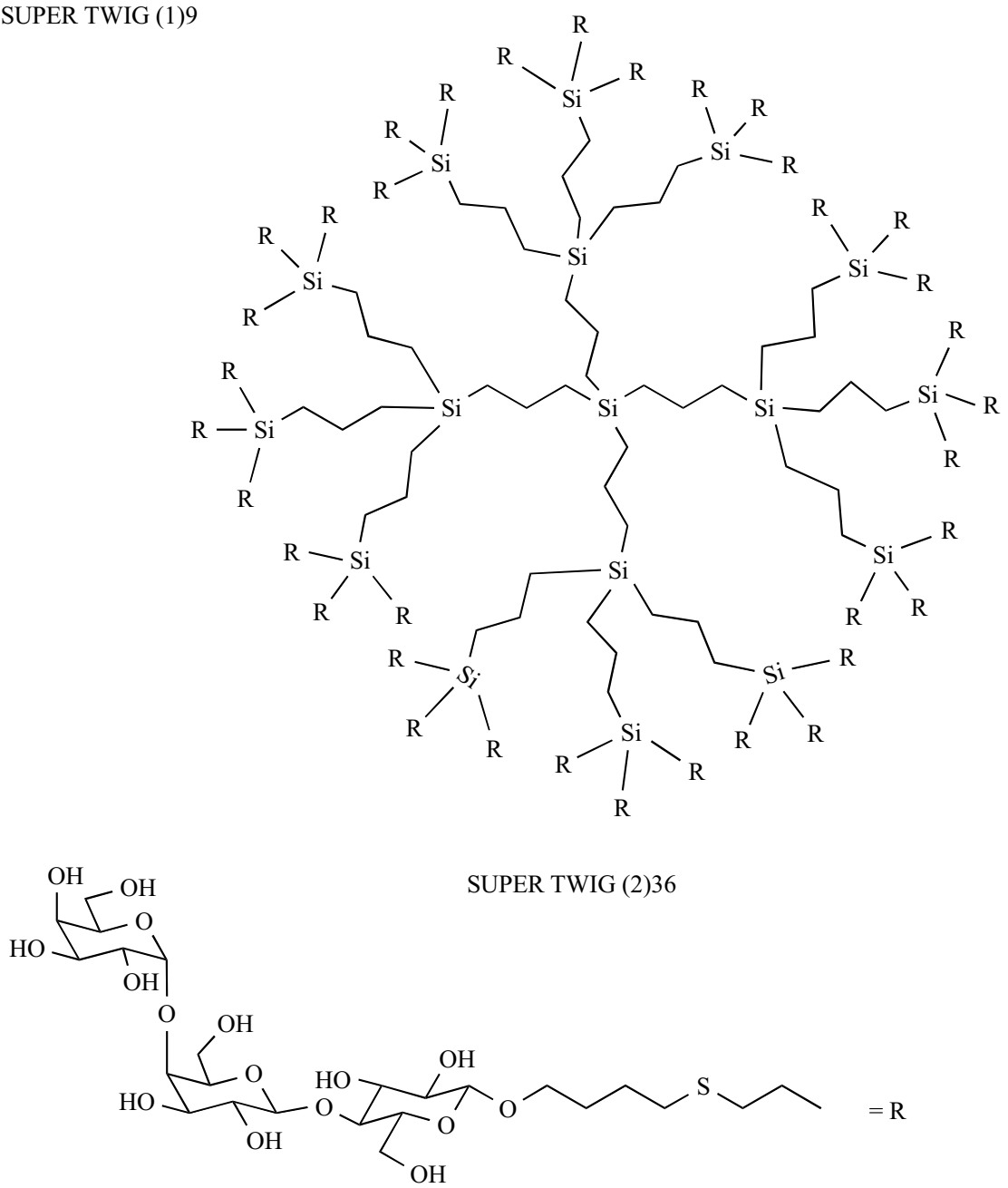

Fig. (5). Chemical structure of dendrimers SUPER TWIG (0)4, (1)4, (1)9, (2)18, and 2(36) functionalized with globotriaose. 


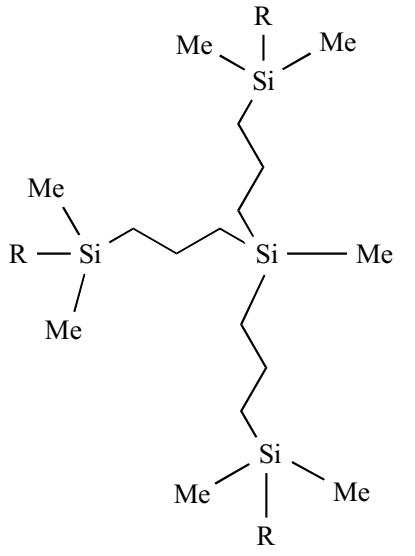<smiles>[R][Si]([R])(C)CCC[Si](C)(C)CCC[Si](C)(C)CCC[Si](C)(C)CCC[Si]([R])([R])C</smiles>

Dumbbell (2)4

Fan (1)3

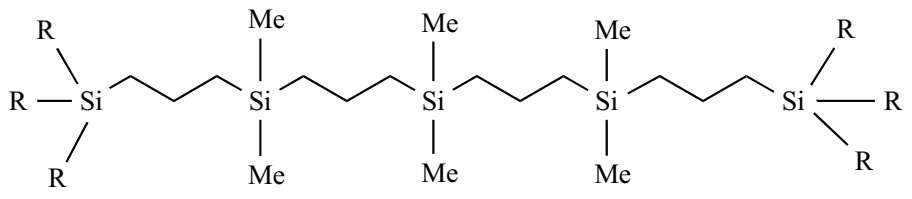

Dumbbell (2)6

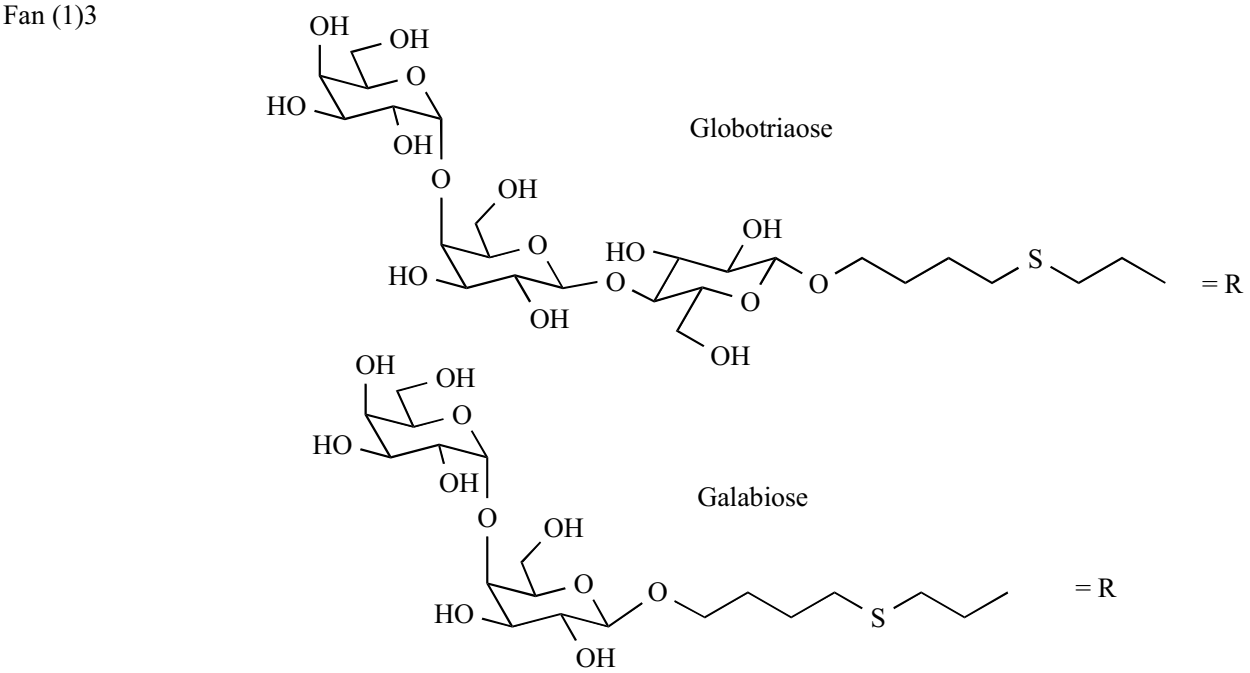

Fig. (6). Chemical structure of dendrimers Fan (1)3, Dumbbell 2(4), (2)6 functionalized with globotriaose and galobiose.

tively were $0.43,0.34,0.21$, and $0.21 \mu \mathrm{mol} / \mathrm{L}$ for Stx 1 and $1.4,11.0,2.1$, and $9.5 \mu \mathrm{mol} / \mathrm{L}$ for Stx2 respectively. In comparison with the previous SUPER TWIG (1)6, only the structure of second generation containing 18 carbohydrates (SUPER TWIG (2)18) showed a better activity against Stx 1 and Stx2. In vivo studies were performed with these new compounds as well. Using a lethal dose of Stx2 intravenously administered to mice, only SUPER TWIG (2)18 suppressed $100 \%$ the effect and mice survived for more than 2 months. Taking into account these biological results and the chemical structures of the dendritic compounds used, some important considerations were assessed: a) at least 4 trisaccharides were required for high affinity and at least 6 trisaccharides are required for an effective activity in vivo; b) distance between terminal silicon atoms in the core structure should be at least $11 \AA$; c) terminal trisaccharides with spacers must be branched from the same terminal silicon atom to present a high density.
Another work of the same group was published very recently presenting a new study on carbosilane dendrimers [54]. Based on the distance between adhesion points in Stx (around $46 \AA$ ), the distance between carbohydrates in the SUPER TWIG (1)6 structure (renamed now as Dumbbell (2)6) was not long enough. A new series of carbosilane dendrimers were prepared presenting 3 (Fan (1)3), 4 (Dumbbell (2)4) and 6 (Dumbbell (2)6) disaccharide galabioses (Gal $\alpha 1$ $4 \mathrm{Gal}$ ) respectively (Fig. 6).

The activity of these new compounds was assessed using biosensor to measure the dissociation constants to Stx 1 and Stx2 as is shown in Table 3 [54].

However, the best result was one order of magnitude worst than the previous data found for Dumbbell (1)6. The $\mathrm{IC}_{50}$ found for inhibition of binding assays of ${ }^{125}$ I-labeled Stxs and Vero cells are presented in Table 4. 
Table 3. $K_{D}(\mu M)$ Measurements Using Biosensors for Carbosilane Dendrimers Against Stx1 and Stx2

\begin{tabular}{|c|c|c|}
\hline Dendrimers & Stx1, $\mathbf{K}_{\mathbf{D}}(\boldsymbol{\mu M})$ & $\mathbf{S t x 2}, \mathbf{K}_{\mathbf{D}}(\boldsymbol{M} \mathbf{M})$ \\
\hline \hline Fan (1)3 Galabiose & 61.1 & 53.9 \\
\hline Dumbbell (1)4 Galabiose & 10.5 & 10.1 \\
\hline Dumbbell (2)6 Galabiose & 1.3 & 1.6 \\
\hline Fan (0)3 Globotriaose & 64.8 & 124 \\
\hline Dumbbell (1)6 globotriaose & 0.11 & 0.21 \\
\hline
\end{tabular}

Table 4. $\mathrm{IC}_{50}(\mu \mathrm{M})$ for Inhibition of Binding Assays with Carbosilane Dendrimers and Stx1 and Stx2

\begin{tabular}{|c|c|c|}
\hline Dendrimers & Stx1, $\mathbf{I C}_{\mathbf{5 0}}(\boldsymbol{\mu} \mathbf{M})$ & $\mathbf{S t x 2}, \mathbf{I C}_{\mathbf{5 0}}(\boldsymbol{\mu} \mathbf{M})$ \\
\hline \hline Fan (1)3 Galabiose & 18.9 & 17.8 \\
\hline Dumbbell (1)4 Galabiose & 23.6 & 23.6 \\
\hline Dumbbell (2)6 Galabiose & 14.2 & 13.6 \\
\hline Fan (0)3 Globotriaose & 21.4 & $>50$ \\
\hline Dumbbell (1)6 Globotriaose & 0.08 & 0.50 \\
\hline
\end{tabular}

Again, the results for the new synthesized compounds were far away of the activity of previously prepared carbosilane dendrimers. The explanation for these results was based in the shorter distance found between sugars in the dendrimers which is critical to have good binding affinities for Stxs.

\section{Heat Labile Enterotoxin}

The heat labile enterotoxin (LT) of E. coli is a choleralike enterotoxin that adheres as cholera toxin does to ganglioside GM1 and causes a somewhat less severe diarrhea due to the same mechanisms [55]. Based on the structural similarities between cholera toxin and heat labile toxin, the group of Schengrund has used the same type of experiments to prove the activity of oligosaccharide-derivatized dendrimers for cholera toxin and heat labile toxin with similar results $[46,47]$.

\section{Bacterial Endotoxins}

Gram-negative bacteria such as Haemophilus influenzae, Escherichia coli, Salmonella enterica, Kelbsiella pneumoniae, Bordetella pertussis, Pseudomonas aeruginosa, Chlamydia psittaci, and Legionella pneumophila present at the outer leaflet of the bilayer membrane a lipopolysaccharide (LPS) component which play a key role in septic shock (sepsis syndrome) [56,57]. This LPS is liberated from the membrane surface when bacteria multiply, die or lyse. LPSs have been recognized as a factor responsible of toxicity in severe Gram-negative bacteria infections causing a systemic response that if uncontrolled can lead to septic shock characterized mainly by fever, hypotension, coagulopathy, and organ failure resulting in many cases in death. The toxic moiety of LPS is a glycolipid named Lipid A considered as a target for the design of drugs against endotoxins (Fig. 7).
This LPS presents an anionic and amphiphilic nature that is an important feature for the design of compounds able to interact with LPS.

David et al., have used polycationic amine-terminated poly(amidoamine) (PAMAM) dendrimers as endotoxin sponge for the therapy of Gram-negative bacterial sepsis (Fig. 7) [58]. Looking for the amphiphilic character of Lipid $\mathrm{A}$, the dendrimers were partially $(25-80 \%)$ alkylated at the surface using 1,2-epoxyalkanes. The affinity of these dendrimers for LPS was evaluated using a high-throughput fluorescence displacement method using BODIPY cadaverine as displacement probe. The best $\mathrm{ED}_{50}(50 \%$ of displacement) was $91 \mathrm{nM}$ found for the PAMAM generation 5 derivative with a $50 \%$ of alkylation (with 2-hydroxyhexyl groups). The dendrimer with a $20 \%$ of alkylation presented an $\mathrm{ED}_{50}$ of $0.28 \mu \mathrm{M}$. In vitro assays of nitric oxide release in LPSstimulated murine macrophage were used to analyze the dendrimer activity. Again, the $5^{\text {th }}$ generation of PAMAM with $50 \%$ of alkylation showed the best $\mathrm{IC}_{50}(50 \mathrm{nM})$. The amphiphilic character of these dendrimers partially functionalized with alkyl groups was critical to achieve good activity to neutralize endotoxins. This compound was used for in vivo studies using mice treated intraperitoneally with a superlethal dose (200 ng/mouse) of LPS. A dose dependent protection of septic shock was observer at 24 hours. Moreover, partial protection was observed up to 36 hours preceding the endotoxin administration indicating a highly prolonged pharmacokinetics.

\section{Type 1 Fimbriated Escherichia coli}

Type 1 fimbriae are adhesion organelles expressed by many Gram-negative bacteria and responsible of the adherence of Escherichia coli to the urinary tract causing common urinary tract infection [59]. This adhesion process is governed by the interaction between type 1 fimbriae and mannose conjugates found at the bladder epithelial cell surface.

Lindhorst et al., have developed carbohydrate multivalent systems to inhibit the adhesion of E. coli mediated by 1 fimbriae. Some of this work was based in simple di, tri and tetramannosides that could corresponding to dendrimers of generation 0 and will not be reviewed here although is an interesting work where some important details about clustering, linkage position and type of spacer are considered [6062]. Glycodendrimers based on multivalent mannopyranosyl structures were prepared as potential inhibitors of the adhesion of type 1 fimbriae [63]. Multivalent systems containing 3 (7), 4 (8), 6 (9), and 8 (10) mannopyranosides attached to the scaffold through a thiourea linkage were prepared and their activities were tested (Fig. 8).

Biological experiments based on inhibition of agglutination using guinea pig erythrocytes and E. coli were carried out. Inhibition titers in these experiments indicated that trivalent (7) and hexavalent (9) mannosyl glycocluster were similar $(0.091 \mathrm{mM})$ and slightly smaller than that found for the octavalent (10) compound $(0.083 \mathrm{mM})$. Tetravalent mannosyl glycocluster $(8)$ presented a higher value $(0.26 \mathrm{mM})$. Also, the features of the linker can play an important role to establish hydrophobic contact with the receptor as was confirmed with the monovalent $p$-nitrophenyl mannopyranoside that showed an inhibition titer of $0.072 \mathrm{mM}$. Control ex- 


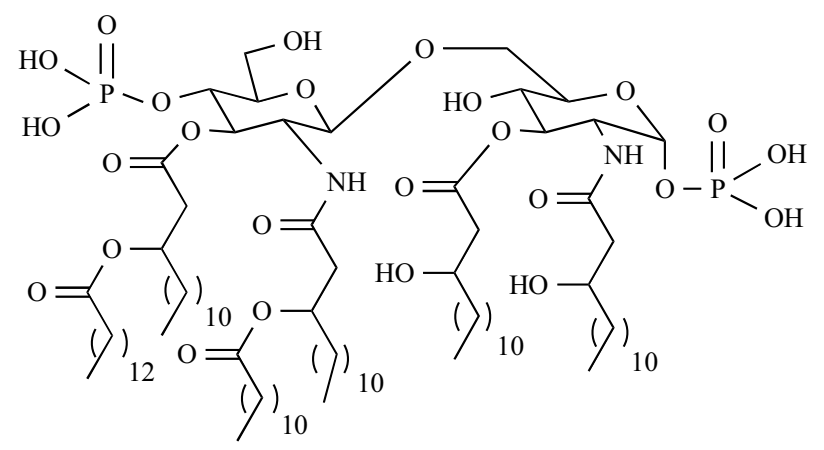

Lipid A<smiles>[R]N(N)N([R])N([R])N</smiles>

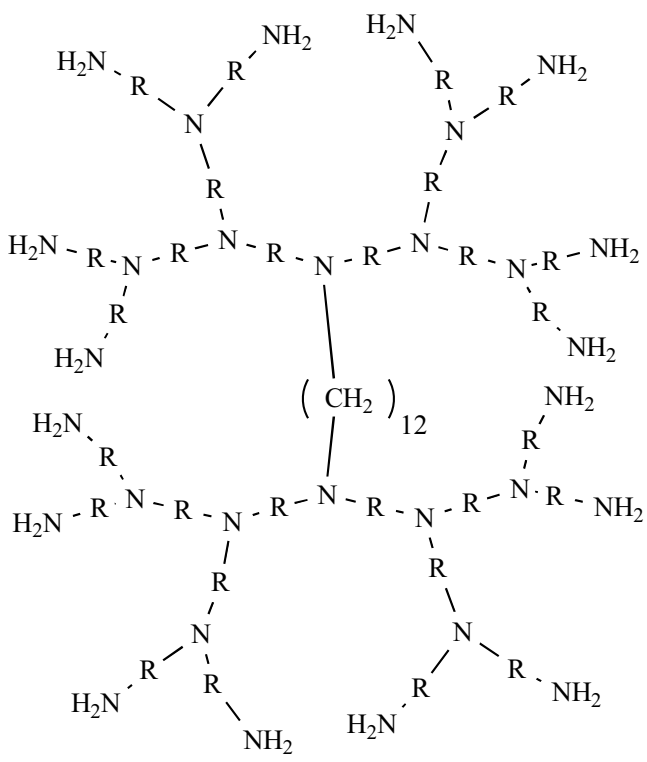

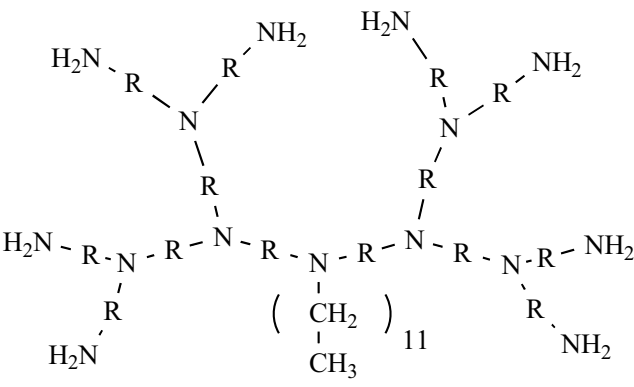

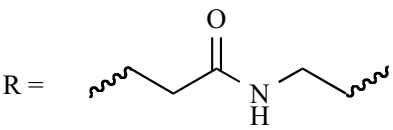

Fig. (7). Lipid A and chemical structures of amine terminated PAMAM derivative dendrimers.

periments using glucose demonstrated the specificity of the binding process for mannosyl derivatives.

Roy, Lee et al., have synthesized polylysine dendrimers with 2 (DP-2), 4 (DP-4), 8 (DP-8), and 16 (DP-16) mannoses with the aim of inhibiting the adhesion of $E$. coli (Fig. 9) [64].

The assay was performed used a neoglycoprotein with 21 mannoses labelled with ${ }^{125} \mathrm{I}\left({ }^{125} \mathrm{I}_{-\mathrm{Man}_{21}}\right.$-ALK-HSA) and $E$. coli. The $\mathrm{IC}_{50}$ found were $22,5,2.8$, and $0.9 \mathrm{nM}$ for dendrimers presenting 2, 4, 8, and 16 mannoses respectively. DP-16 showed an increase of inhibition activity of 12500 fold in comparison with the monovalent methyl $\alpha$ mannopyranoside. The studies revealed important issues concerning the importance of the mannose orientation on these types of multivalent systems. The affinity of these compounds was strongly dependent on the distance between mannose residues; a large distance $(>20 \mathrm{~nm})$ seems to be an adequate separation between two mannoses to interact in a multivalent way with adhesins presented in 1 fimbriae $E$. coli.

Pieters et al., have developed small multivalent systems $[65,66]$, glycodendrimers [66] and glycopolymers [66] to 


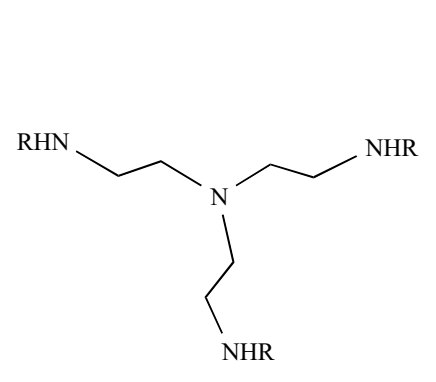

7

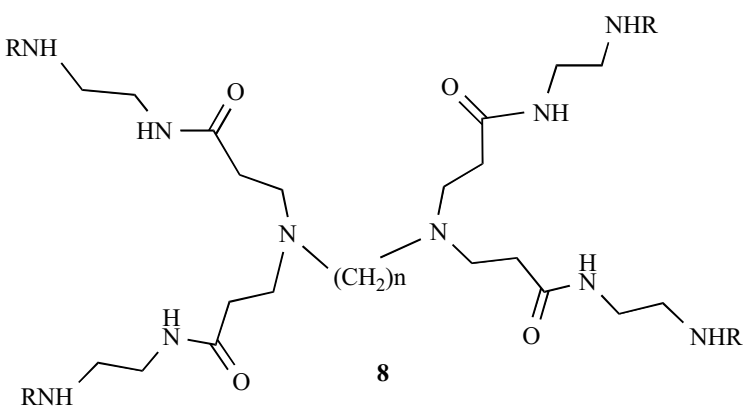

$\mathrm{n}=2,6,12$

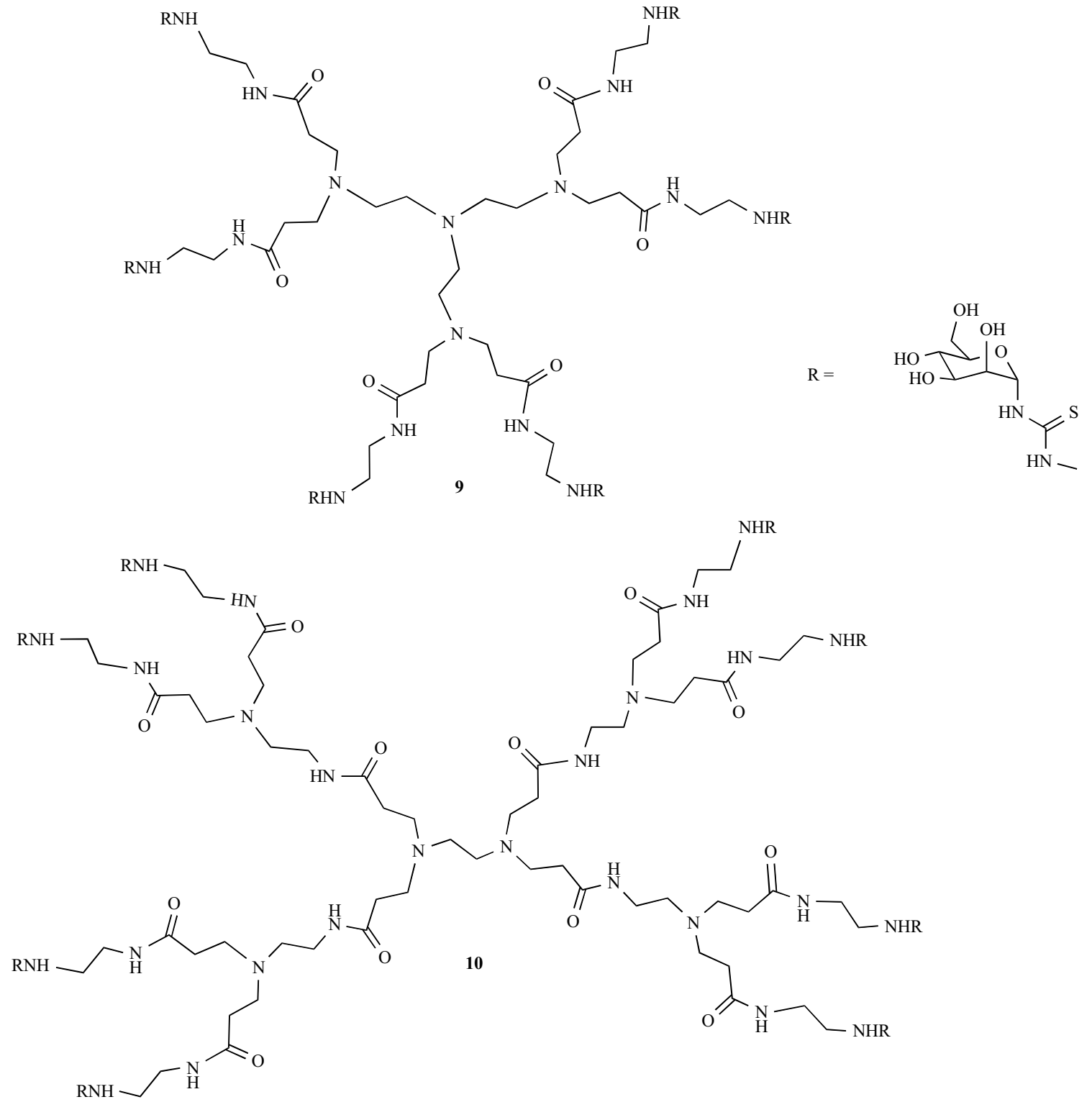

Fig. (8). Poly(amido amine) dendrimers with 3 (7), 4 (8), 6 (9), and 8 (10) mannopyranoses.

inhibit the adhesion of type 1 fimbriated uropathogenic $E$. coli. Two type of scaffold were prepared based on bis-3aminoprop-1-ynyl benzene and PAMAM (Fig. 10).

The biological activity was tested in an ELISA-based assay using type 1 fimbriated E. coli and T24 cell line de- rived from human urinary bladder epithelium. These assays indicated that systems based on PAMAM were better than those based on the aromatic scaffold (for the same number of ligand at the surface). PAMAM presenting 8 (3) ((Fig. 3) and 16 (11)) mannoses showed an $\mathrm{IC}_{50}$ of 37 and $19 \mu \mathrm{M}$ respec- 


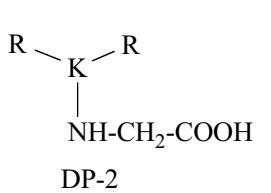

DP-2<smiles>[R][R][X]([R])([R])NCC(=O)O</smiles>

DP-4
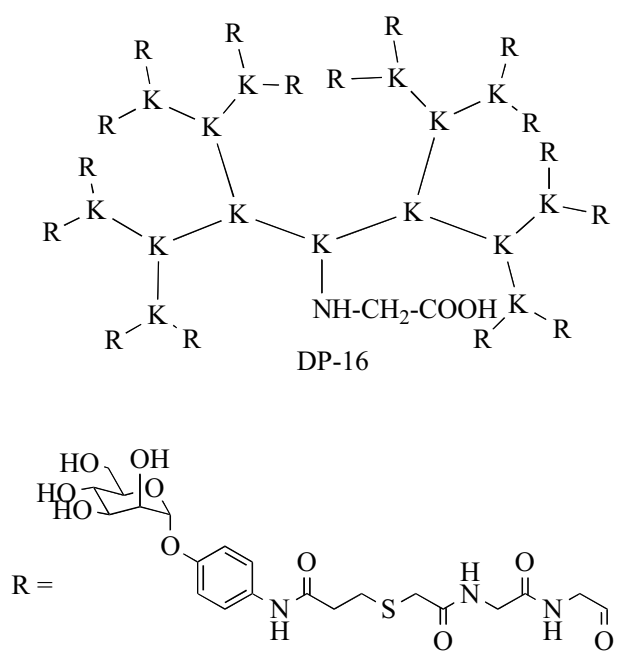

$\mathrm{K}=\overbrace{\mathrm{HN}}^{\mathrm{CO}}$

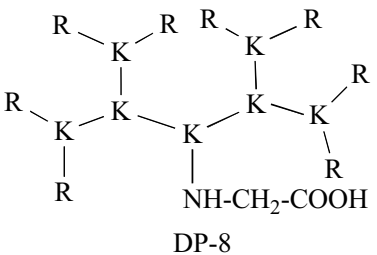

DP-8

Fig. (9). Polylysine dendrimers DP-2, DP-4, DP-8 and DP-16 functionalized with mannose.

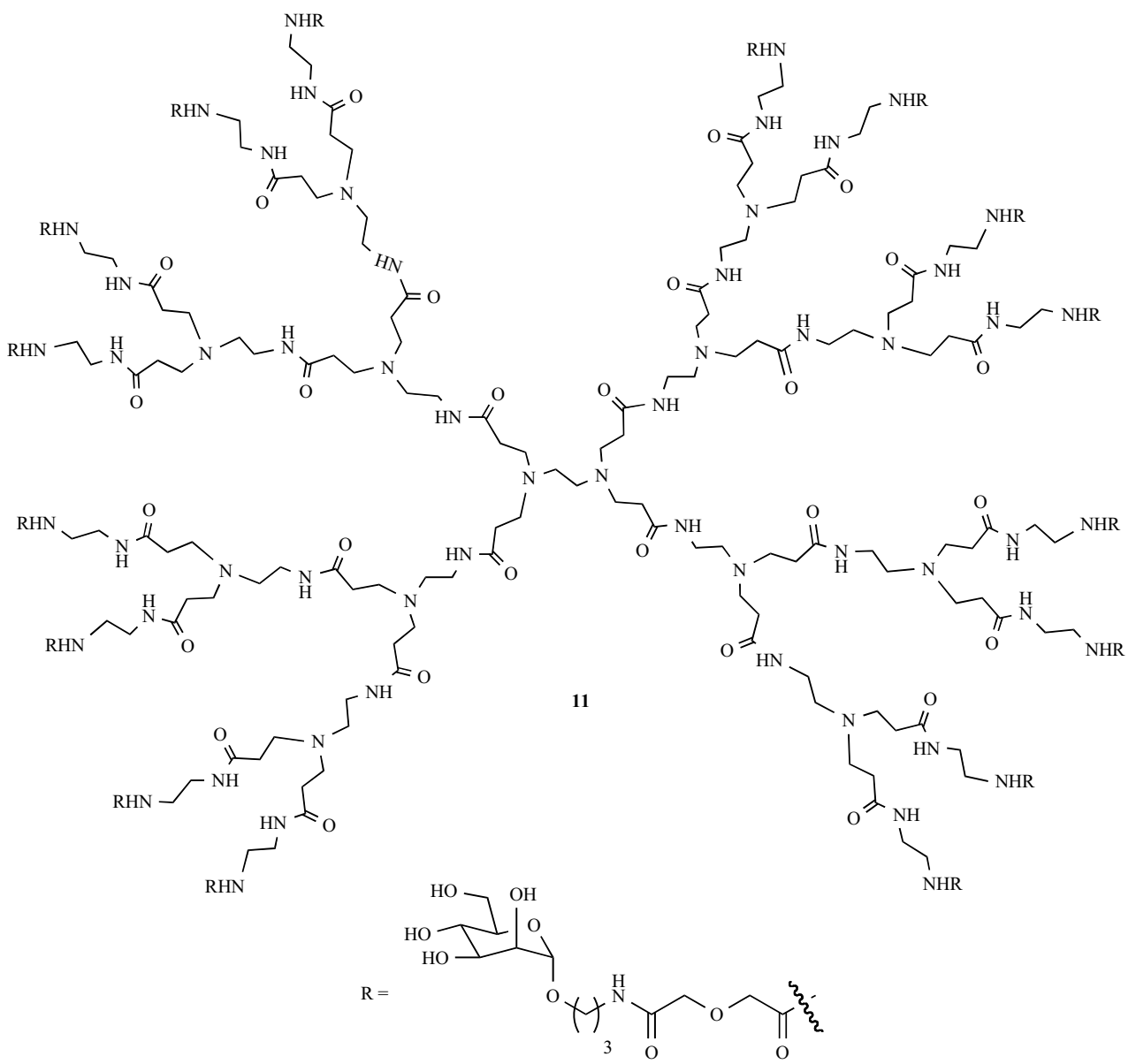

Fig. (10). Mannosyl derivative PAMAM 2G(11). 
tively. The dendrimer with aromatic scaffold (6) (Fig. 2) and 8 mannoses at the surface showed an $\mathrm{IC}_{50}$ of $72 \mu \mathrm{M}$. Again, these studies demonstrated the importance not only of the number of ligands but the size and shape of the scaffolds and linkers used.

One of the general strategies to test the activity of compounds as bactericides is the use of E. coli as a general type of Gram-negative bacteria model. Banthia et al., have prepared oligourethane dendronized with PAMAM (Fig. 11) [67].

The activity of these compounds was tested using a method to observe inhibition zone of growth with bacteria on a solid agar medium. This dendronized system by itself was not able to inhibit the bacteria growth; however, when it was doped with silver, a clear inhibition was observed. These materials could be considered as promising systems for biomedical applications.

Urbanczyk-Lipkowska et al., have prepared two type of dendrimers based into amino acids (Lysine) to inhibit infection by $E$. coli $[68,69]$. Minimal inhibitory concentrations (MIC), the concentration at which $100 \%$ inhibition of growth, were evaluated. The values found for all compounds prepared were in the $\mu \mathrm{M}$ range.

Cooper et al. have developed quaternary ammonium functionalized poly(propylene imine) dendrimers (12) as antimicrobials (Fig. 12) [70].

The biocide activity was evaluated using a bioluminescence method. Some key structural factors were analyzed based on their influence in the activity. The size of the dendrimer, the length of hydrophobic chain in the quaternary group and the counteranion were very important issues.

\section{Streptococcus suis}

Streptococcus suis is a Gram-positive bacteria responsible of meningitis, septicemia, and pneumonia in pigs, swine and other domestic animals and also meningitis in humans who have been in contact with pigs $[71,72]$. This bacteria present a galactosyl- $\alpha$-1-4-galactose-binding adhesin implicated in the adhesion process of the bacteria to the host cells [73]. Magnusson et al., in 1997 prepared a small tetravalent galabiose system to inhibit the hemagglutination by Streptococcus suis at nanomolar concentration (Fig. 13) [74].

Inhibition experiments of agglutination of human erythrocyte by two types of $S$. Suis bacteria $\left(\mathrm{P}_{\mathrm{N}}\right.$ and $\left.\mathrm{P}_{\mathrm{O}}\right)$ were performed. Complete inhibition using this tetravalent galabiose was found for 3 and $2 \mathrm{nM}$ for each type of $S$. Suis bacteria respectively. This example was considered at that time as the first example of inhibition of bacteria adhesion at nanomolar range.

Pieters et al., described the preparation of galabiose dendrimers and their inhibition activities against Streptococcus suis [75]. Assays to study the inhibition of hemagglutination of human erythrocytes induced by two subtypes of Streptococcus suis $\left(\mathrm{P}_{\mathrm{N}}\right.$ and $\left.\mathrm{P}_{\mathrm{O}}\right)$ was performed. The MIC (minimal inhibitory concentration) required for complete inhibition of the agglutination process were measured. The MIC found for

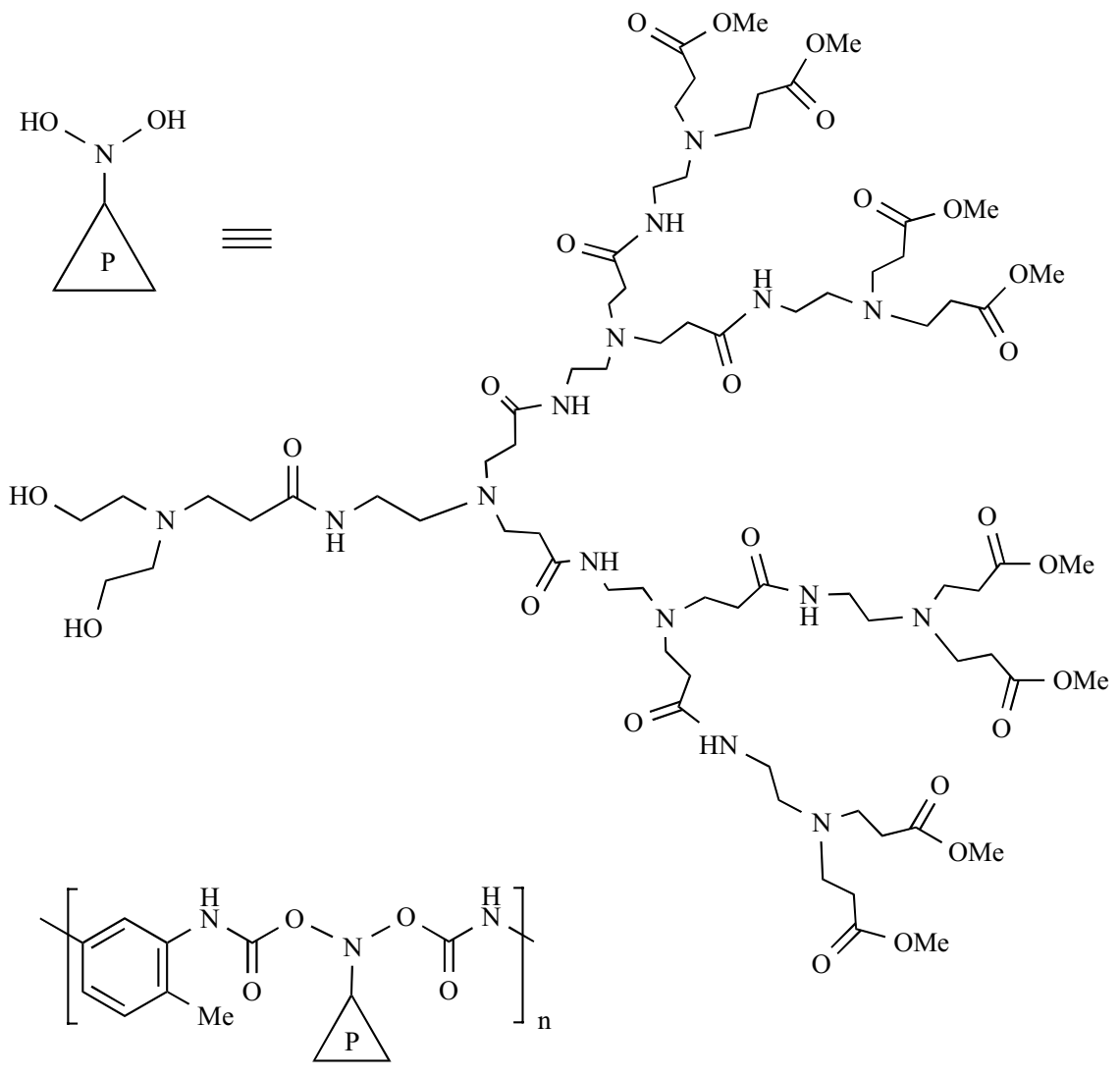

Fig. (11). Chemical structure of PAMAM dendronized oligourethane. 


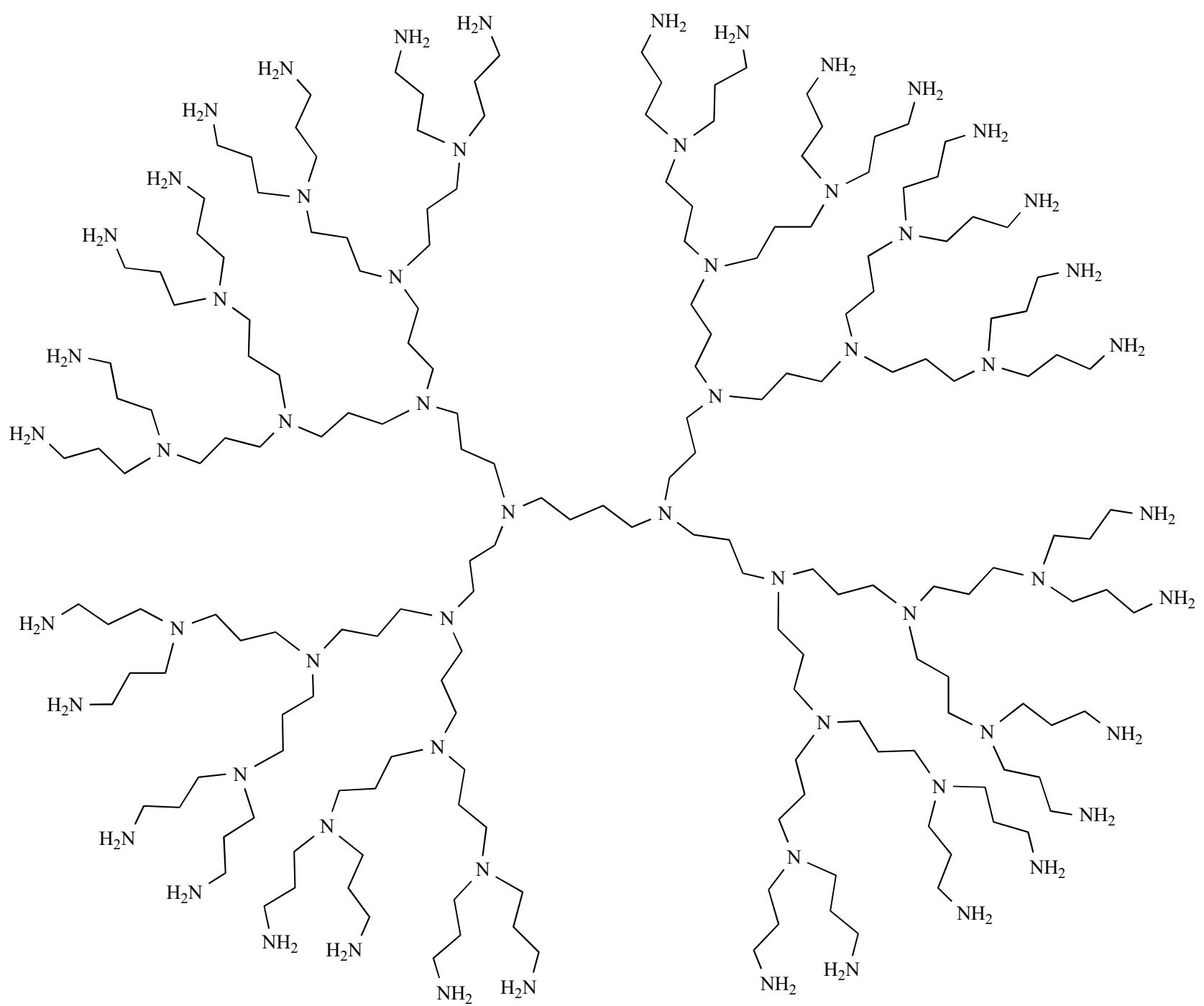

Fig. (12). Poly(propylene imine) 2G dendrimer (12).

all compounds containing 2 (13), 4 (5), and 8 (3) galabioses with different linkers were in the nanomolar range (Fig. 14).

The octavalent galabiose PAMAM presented a MIC of $0.3 \mathrm{nM}$ for the $\mathrm{P}_{\mathrm{N}}$ subtype (3000 fold more potent than the monovalent compound) and the authors claim that this is the first example where a carbohydrate compound presents a subnanomolar activity in the inhibition of bacterial adhesion. Biosensor was used as a complementary experiment to test the activity of these compounds. Pigeon ovomucoid, a protein rich in galabiose was immobilized on the sensor chip surface of the biosensor. S. suis $\mathrm{P}_{\mathrm{N}}$ was flowed over this surface in the presence or absence of inhibitors at different concentrations. $\mathrm{IC}_{50}$ were obtained for each compound in the range of 150-300 $\mathrm{nM}$ for divalent inhibitors and $7 \mathrm{nM}$ for tetravalent compound and octavalent PAMAM. These studies provide important information about the role of the mobility and orientation of ligands and valency of multivalent scaffolds in relationship with the enhancement of binding affinities.

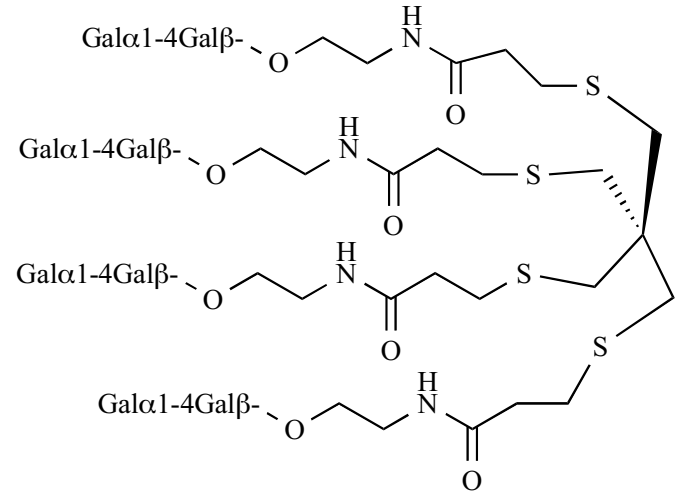

Gal $\alpha 1-4 \mathrm{Gal} \beta=$

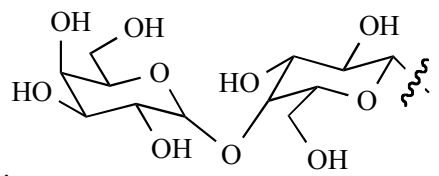

Fig. (13). Tetravalent galabiose. 
<smiles>CC(=O)c1cc(OCCNC(=O)COCC(=O)NCCCOCCOCCOCCCN)cc(OCCNC(=O)COCC(=O)NCCCOCCOCCOCCCN)c1</smiles>

13

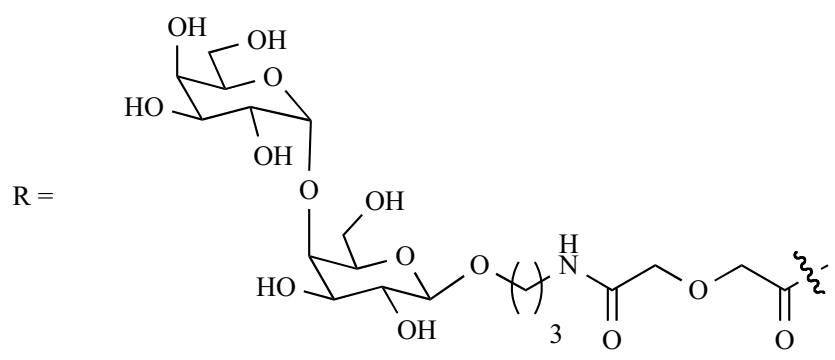

Fig. (14). Chemical structure of galabiose functionalized divalent system (13).

\section{Staphylococcus aureus}

Staphylococcal disease and its role in sepsis and abscess formation were described for the first time in 1880 and 1882 by Ogston. More than 100 years later, Staphylococcus aureus (a Gram-positive bacteria) remains a dangerous pathogen in humans that can cause illnesses ranging from minor skin infections to life-threatening diseases such as pneumonia, meningitis, endocarditis, Toxic shock syndrome (TSS), and septicemia [76].

The dendrimers described by Cooper et al. [77] and Urbanczyk-Lipkowska et al. $[68,69]$ for $E$. coli were also tested against a Gram-positive bacteria Staphylococcus aureus NCTC 4163. Very similar activities in this infection model with $S$. aureus were also found in the E. coli studies.

\section{Actinomyces naeslundii}

A. naeslundii is a Gram-positive bacterium that colonizes oral cavities. During this colonization process, A. naeslundii co-aggregate with Streptococcus oralis through galactose residues present at the surface of $S$. oralis and an adhesin of A. naeslundii pili [78]. Davis et al., have developed a new type of multivalent systems named glycodendriproteins consisting in the functionalization of proteins with glycodendrons (Fig. 15) [79].

These types of structures mimicking glycoproteins avoided the problem of glycoforms. Galactose-dendri-proteins were tested as potential inhibitors of co-aggregation of A. naeslundii and $S$. oralis. The dendriprotein with a flexible bi-antennary galactosyl structure was a potent inhibitor with an $\mathrm{IC}_{50}$ of $20 \mathrm{nM}$ (a million fold more potent than lactose). This result opens a new avenue to design de novo glycoproteins with important biological activities.

\section{FUNGAL INFECTION}

One of the most common infections produced by fungi is that caused by Candida albicans. C. albicans is a normal

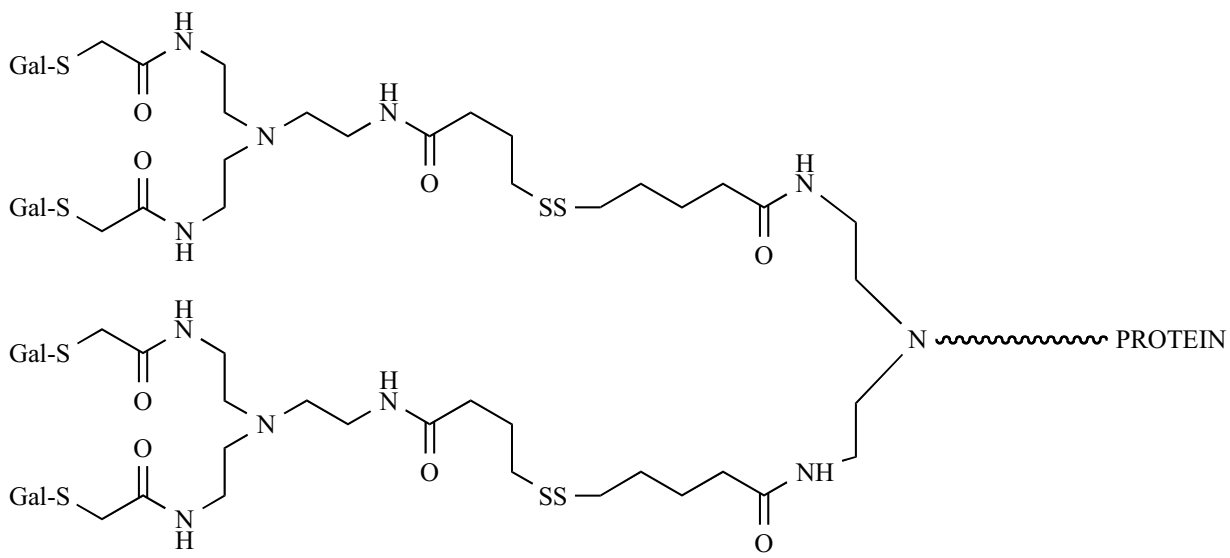

Fig. (15). Tetravalent galactosyl dendriprotein. 
inhabitant of the human mouth and gastrointestinal tract. Under normal circumstances, $C$. albicans colonizes humans with no harmful effects, although overgrowth may result in candidiasis in skin or mucosa [80]. Systemic candidiasis is often observed in immunocompromised individuals such in transplantation, malignancy or AIDS. Different forms of $C$. albicans are also recognized by different lectins that are expressed at the surface of target cells [81].

To our best knowledge, there is only one example described by Urbanczyk-Lipkowska et al., where dendrimers are used as anti-infective agents in a $C$. albicans infection process. These authors have developed a low molecular mass lysine dendrimer with antimicrobial activity [68]. These small dendrimers are functionalized at the surface by arginin residues and presented minimal inhibition concentrations between 72 and $69 \mu \mathrm{M}$.

\section{PRION PROTEIN INFECTION}

Stanley Prusiner discovered almost 25 years ago a new infective agent, a protein named prion. The prion protein is the product of a normal gene expressed mainly in neural tissue and presents several $\alpha$-helix and few $\beta$-sheets in its natural configuration known as $\operatorname{PrP}^{\mathrm{C}}$. This protein adopts an abnormal configuration upon contact with the $\beta$-sheet-rich infectious form of the protein known as $\mathrm{PrP}^{\mathrm{Sc}}$ after scrapie, an old recognized disease of sheep [82]. These types of structures are found in several neurodegenerative disorders such as Creutzfeldt-Jakob disease in humans, bovine spongiform encephalopathy, etc. Prusiner et al., have demonstrated that highly branched polyamidoamine PAMAM dendrimers were able to eliminate $\mathrm{PrP}^{\mathrm{Sc}}$ in a very efficient way. PAMAM generation 4.0 presenting 64 amine groups at the surface (see Fig. (10) for PAMAM 2G (11) with 16 amine groups or Fig. (16) for $3 G$ (14) with 32 amine groups) was able to removed prion protein in a dose and time dependent manner with $\mathrm{IC}_{50}$ around $80 \mathrm{ng} / \mathrm{mL}[83,84]$.

For these experiments, chronically scrapie-infected neuroblastoma $\mathrm{N} 2 \mathrm{a}(\mathrm{ScN} 2 \mathrm{a})$ cells were used. In these studies was demonstrated that the size of the dendrimer and the number of amine groups at the surface were critical for an

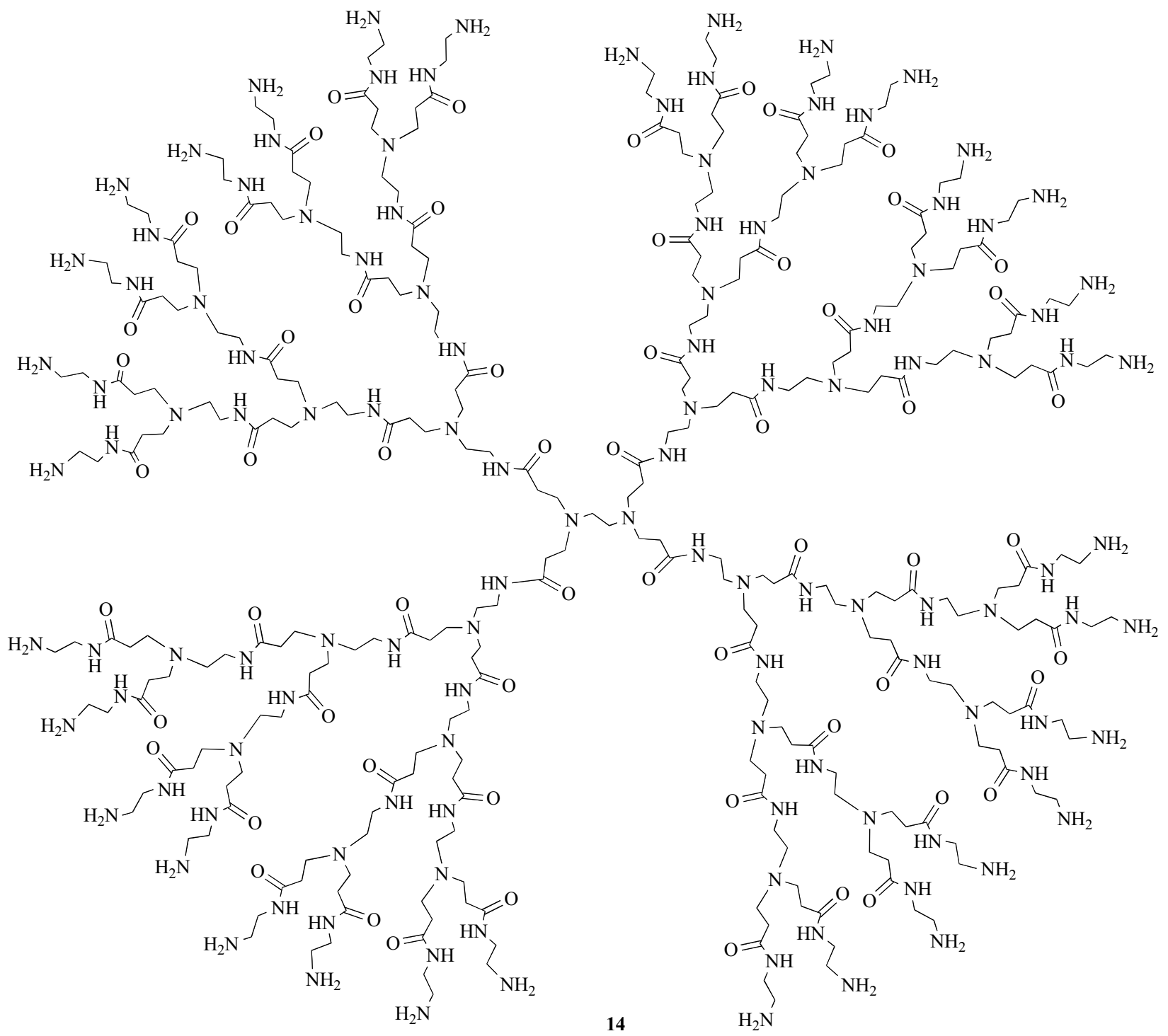

Fig. (16). PAMAM 3G (14). 
efficient activity. These compounds required an acidic media to destroy $\mathrm{PrP}^{\mathrm{Sc}}$; however, the mechanism to eliminate prion proteins was not clarified. It seems that the presence of dendrimers make fibrils sensitive to protease $\mathrm{K}$ degradation. A potential use of these dendrimers as reagents for prion decontaminants to remove prions from skin, surgical instruments, surfaces, etc. has been envisaged [84].

Very recently, Cladera et al., have studied the aggregation of the Alzheimer amyloid peptide $A \beta 1-28$ and human prion protein PrP185-208 in the presence of PAMAM dendrimers [85-87]. Higher generations of PAMAM G3-G5 led to a smaller amount of fibrils formed. $1 \mu \mathrm{M}$ of PAMAM G5 was enough to inhibit the fibril formation. The mechanism proposed was based on two actions: a) interaction of dendrimers with the peptide monomers inhibiting the fibril growth and b) breaking the existing fibrils.egaard et al., have used a guanidinium modified dendrimer (15) based on the second generation of poly (propylene imine) (PPI) (2) to destabilized the fibril formation of a peptide fragment of the PrP (106-126) in water at a concentration of $20 \mu \mathrm{M} / \mathrm{mL}$ (Fig. 17) [88].

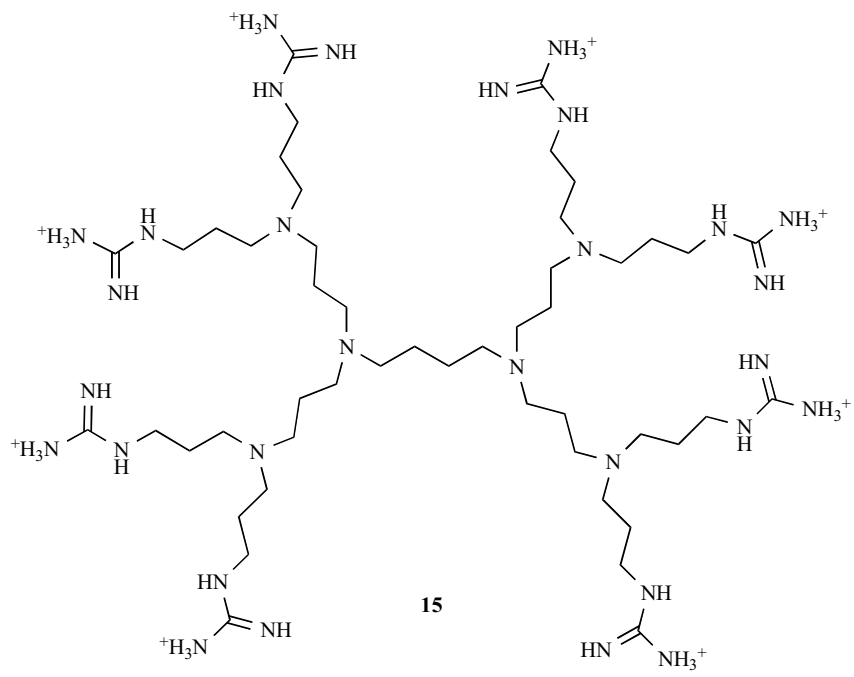

Fig. (17). Guanidinium modified poly(propylene imine) (PPI) 2G (15).

The guanidinium groups at the surface were easily protonated in water due to the high $\mathrm{p} K_{a}$ compared with the amino groups of PPI. The effect produced by this dendrimer seems to solubilize the protein.

A final example described by Lehmann et al. using cationic phosphorus-containing dendrimers (P-dendrimers) will be reviewed [89]. Protonated tertiary amine end-groups were presented at the surface of these compounds (Fig. 18).

The compounds presented some advantages in comparison with PAMAM dendrimers such as a higher stability against nucleophilic degradation due to the phosphorous atoms and the high hydrophilic nature, decreasing rapid elimination when applied. These dendrimers were able to clear $\mathrm{PrP}^{\mathrm{Sc}}$ in the $\mathrm{SN} 2 \mathrm{a}$ cells with $\mathrm{IC}_{50}$ in the $\mathrm{nM}$ range $(600$ $\mathrm{nM}, 45 \mathrm{nM}$, and $75 \mathrm{nM}$ for pd-G3, pd-G4, and pd-G5 respectively). Again, the mechanism proposed was based on the interaction of the dendritic structures with the fibrils, disrupting these aggregates and doing easier their degradation by protease $\mathrm{K}$. Cytotoxic studies demonstrated that these $\mathrm{P}$ dendrimers were less toxic than PAMAM and also they presented a wide biodistribution throughout the body. In vivo studies using mice infected with $\operatorname{PrP}^{\mathrm{Sc}}$ demonstrated that $\mathrm{P}$ dendrimers inhibited the generation of $\mathrm{PrP}^{\mathrm{Sc}}$ in spleen. These authors considered that the treatment with P-dendrimers as a post-exposure prion prophylaxis could open an interesting therapeutic approach to prion diseases.

\section{VIRAL INFECTION}

This is the area of application where more efforts have been done respect to develop new anti-infective agents based on dendrimers. Recently, a review describing dendrimers as antivirals has been published [90]. Here, we intend to update the information presented in that review with the most recent publications concerning dendrimers as antiviral drugs. Again, this section will be divided for each different viral agent.

\section{HIV-1, HIV-2, AND SIV}

Infection by Human Immunodeficiency Virus (HIV) is a global health problem although, especially dramatic in developing countries in sub-Saharan Africa and Asia where the vast majority of infected patients do not have access to antiretroviral drugs. Most recent research in this topic is concentrated on vaccine development and mainly on developing microbicides [91,92]. Most of the work concerning dendrimers is oriented to developing these microbicides of topical use.

We would like to focus mainly in one negatively-charged dendrimer which has been formulated as a Gel called SPL7013 (Fig. 19).

This dendrimer was developed by a pharmaceutical company in Australia Starpharma Pty Limited together with a large series of other dendritic compounds. Biological studies in vitro and in vivo with SPL7013 indicated that this compound could be the best candidate to attain the market as the first dendrimer with a biomedical application. A study performed by Dezutti et al., demonstrated that a formulation of SPL7013 (5\%) showed a low epithelial toxicity and was highly effective to prevent infection by HIV-1 of PMBCs, macrophage and transfer of virus from epithelial cells to PMBCs [93]. These promising results indicated that this type of formulated drugs could be used as promising candidates to be applied as microbicides. More detailed studies about the toxicity of SPL7013 gel formulations were performed by Patton et al., [94]. A repeated daily vaginal use of $1-3 \%$ of SPL7013 gels were well tolerated (similar results were found to rectal use); however, 5\% of SPL 7013 produce deleterious effects on the cervicovaginal environments [94]. SPL7013 was also tested in a HIV infection colorectal tissue explants model [95]. This study demonstrated the low toxicity of formulated SPL7013 and the highly effectiveness in prevention HIV infection in this model. In vivo studies were carried out using SPL7013 gel as a topical microbicide in a vaginal transmission of SHIV in macaques [96]. The results showed that neither SPL7013 nor placebo gels produced any signs of mucosal irritation after vaginal application. SPL7013 (5\%) gel protected 6 of 6 macaques (100\% of protection) while SPL7013 (3\%) gel protected only 83.3\%. McCarthy et al., 


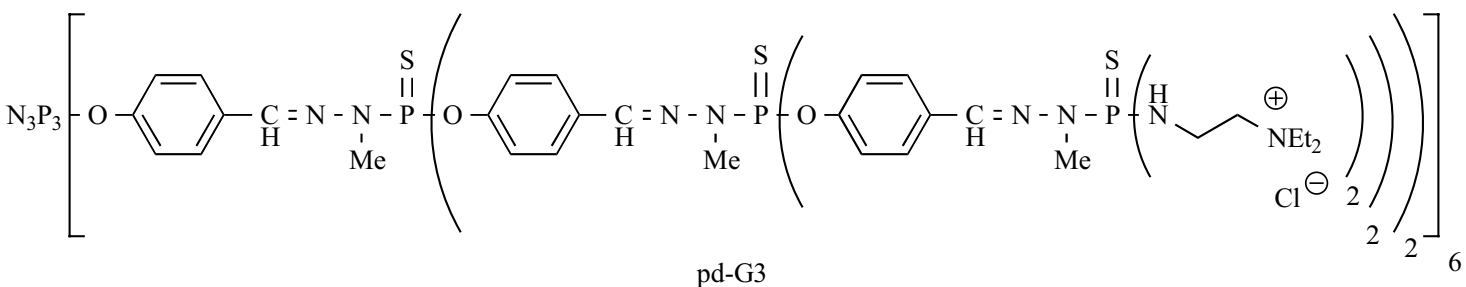

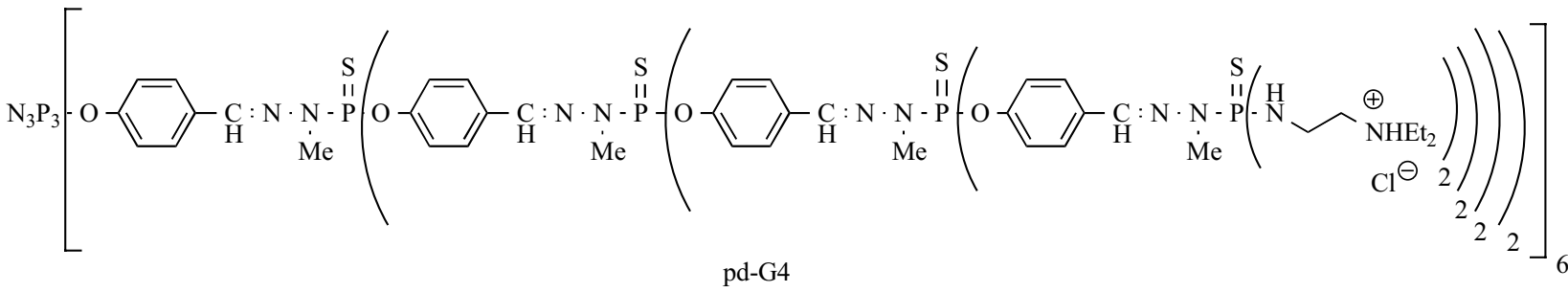

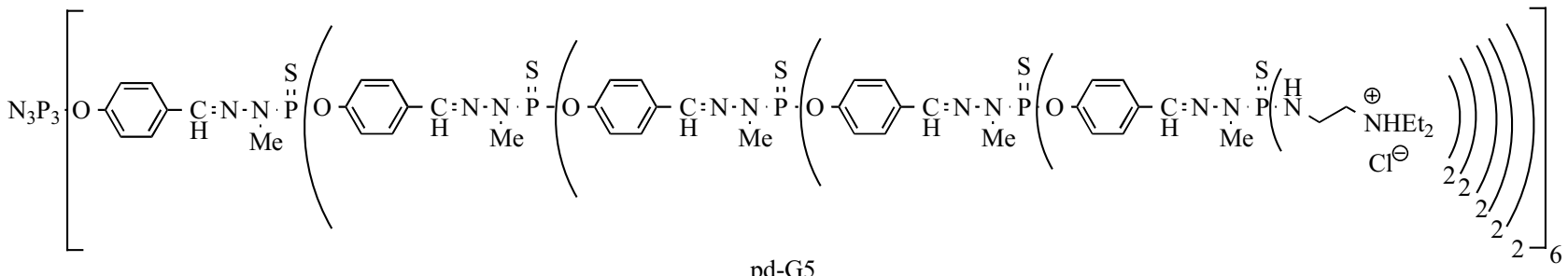

Fig. (18). Chemical structures of phosphorous dendrimers pd-G3, pd-G4, and pd-G5.

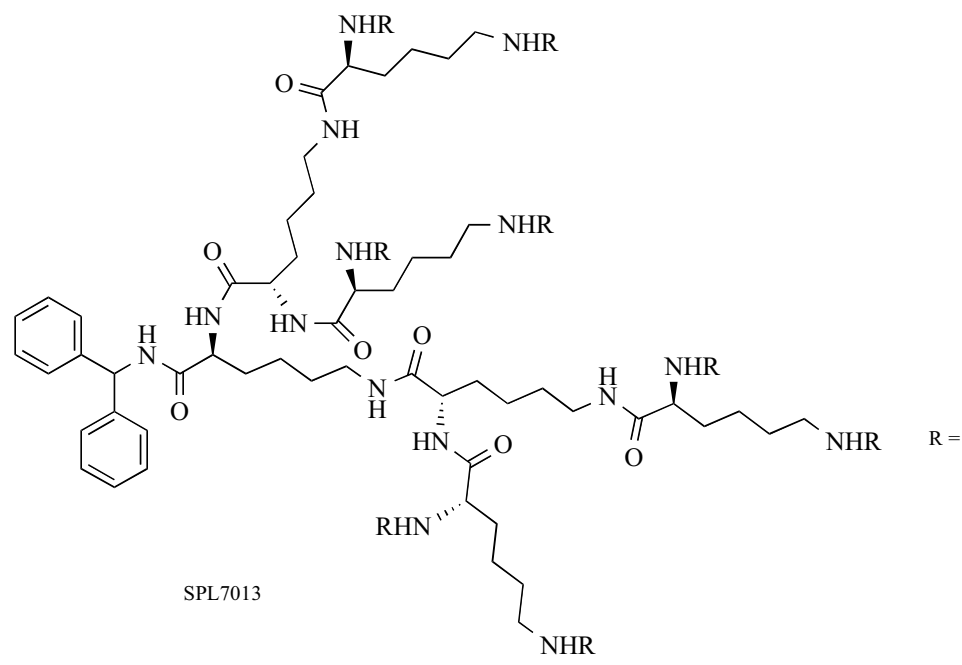

Fig. (19). Chemical structure of SPL7013.

from the company Starpharma Pty Limited described in detail the process developed to achieve the lead compound SPL7013 [97]. Many parameters were evaluated to arrive to the final dendrimer structure easy to be prepared in large scale as a single molecule. The clinical drug is known as VivaGel and is the first dendrimer submitted to the United States Food and Drug Administration (FDA) as investiga-

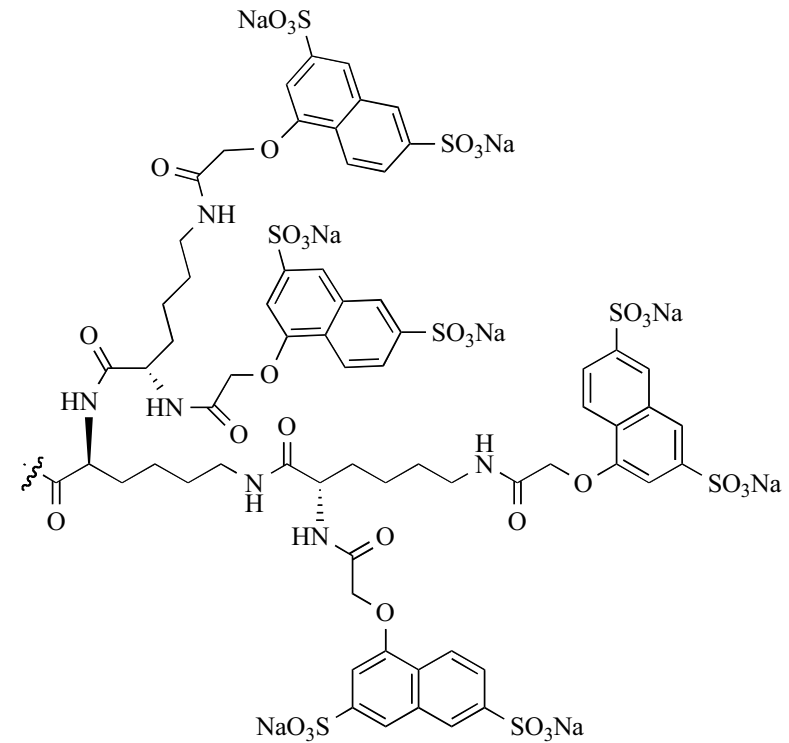

tional new drug application in 2003. Also, Phase I clinical trials were carried out involving 36 healthy women with successful results.

Another approach to inhibit HIV entry and dissemination is based on blocking the interaction with galactosyl ceramide as a receptor in $\mathrm{CD}_{4}{ }^{+}$cells [98]. Blanzat, Turrin et al. have 
prepared acid-terminated dendrimers non-covalently assembled with galactosyl ceramide analogues [99]. Cinamic acid terminated dendrimers were combined with aminolactitol to form analogues of galactosyl ceramides (Fig. 20).

HIV inhibition activities and cytotoxicities of these dendrimers were evaluated in vitro using CEM-SS cells (human T4-lymphoblastoid cell line) as model. The values found for each compound are represented in Table 5.

It is clearly observed that the different $\mathrm{IC}_{50}$ found not only depend of the number of sugars at the surface but also of the size and shape of the dendritic core.
Other examples of dendrimers with anti-HIV activity are collected in the review of Schengrund et al. [90]

\section{Herpes Simplex Virus (HSV) Infection}

Genital human herpes virus infection is one of the most prevalent sexual transmitted diseases (STDs). HSV-1 and 2 cause mucocutaneous infection, such as herpes labialis and herpes genitalis. After primary or initial infection the virus persists for life in a latent form in neurons of the host, periodically reactivating. Currently, no cure is available [100].
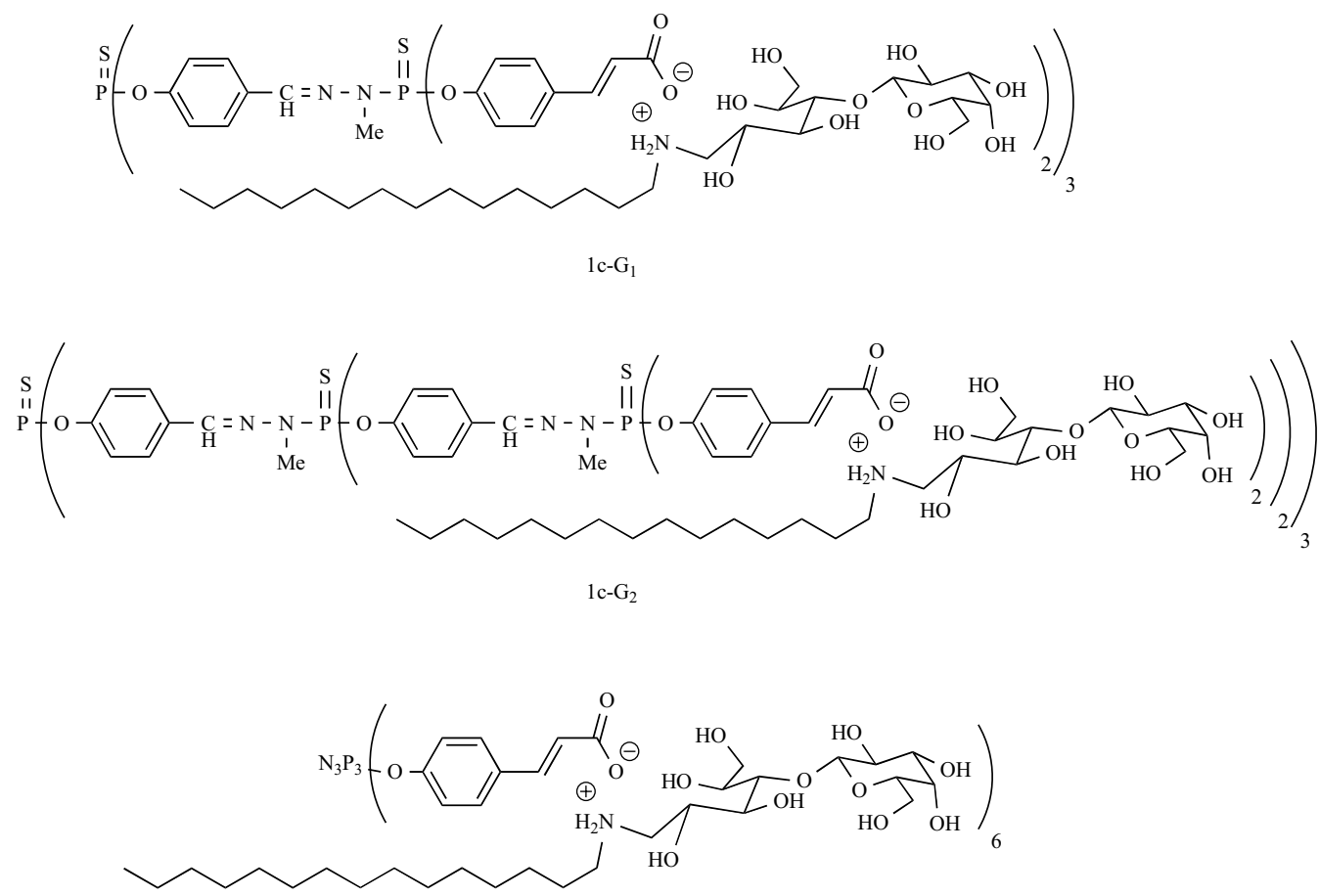

$2 \mathrm{c}-\mathrm{G}_{0}$

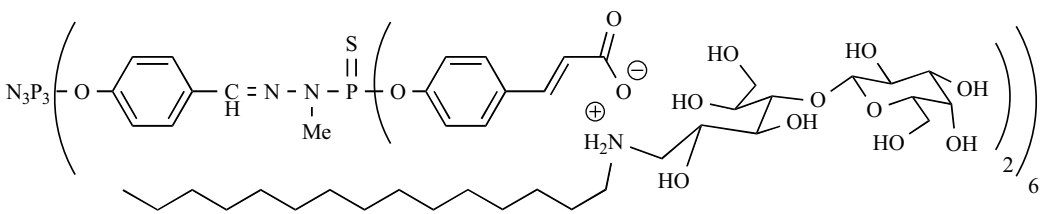

$2 \mathrm{c}-\mathrm{G}_{1}$

Fig. (20). Non-covalent assembled galactosyl ceramides analogues dendrimers $1 \mathrm{c}-\mathrm{G}_{1}, 1 \mathrm{c}-\mathrm{G}_{2}, 2 \mathrm{c}-\mathrm{G}_{0}$, and $2 \mathrm{c}-\mathrm{G}_{1}$.

Table 5. Inhibition Activities for Galactosyl Ceramide Analogue Dendrimers

\begin{tabular}{|c|c|c|c|}
\hline Compound & Number of sugars & IC $_{\mathbf{5 0}}(\boldsymbol{M} \mathbf{M})$ & $\mathbf{C C}_{\mathbf{5 0}}(\boldsymbol{M})$ \\
\hline \hline monomer & 1 & 50 & 70 \\
\hline $1 \mathrm{c}-\mathrm{G}_{1}$ & 6 & 2.1 & 3.5 \\
\hline $1 \mathrm{c}-\mathrm{G}_{2}$ & 12 & 1.1 & 2.9 \\
\hline $2 \mathrm{c}-\mathrm{G}_{0}$ & 6 & 0.37 & 9.3 \\
\hline $2 \mathrm{c}-\mathrm{G}_{1}$ & 12 & 0.12 & 3.9 \\
\hline
\end{tabular}


One of the promising compounds developed against HSV is a sulphated polylysine dendrimer named SPL2999 (also known as BRI-2999) which has been already reviewed (Fig. (21) [90].

BHA.Lys.Lys $2 . \operatorname{Lys}_{4} \cdot \operatorname{Lys}_{8} \cdot \operatorname{Lys}_{16}\left(\mathrm{NHCSNH}\left(\mathrm{Napth}\left(\mathrm{SO}_{3} \mathrm{Na}\right)\right)_{32}\right.$

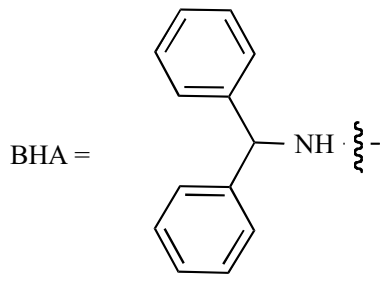

SP2999 or BRI-2999

Fig. (21). Chemical structure of SPL2999 or BRI-2999.

An evolution of this compound is the dendrimer SPL7013 (commented previously as an anti-HIV agent). This dendrimer have been tested (formulated and unformulated) as a microbicide candidate against genital herpes in mouse and guinea pig models and it was already analyzed in a previous review [90]. A new study concerning the antiviral efficacy, mechanism of action, and toxicity of SPL7013 has been recently published [101]. Vero cells were infected with $2.0 \mu \mathrm{g} / \mathrm{mL}$ of HSV-1 or $0.5 \mu \mathrm{g} / \mathrm{mL}$ of HSV-2. Two types of experiments were performed, pre-treatment (PT) of cells with SPL7013 or treatment of infected cells (INF). The results are shown in Table 6.

SPL7013 inhibited virus internalization of both HSV-1 and $\mathrm{HSV}-2$ at concentrations bigger than $3 \mu \mathrm{g} / \mathrm{mL}$. Also, SPL7013 showed post-exposure activity on HSV infection indicating a therapeutic activity. This type of dendrimers could be used in prevention and treatment of HSV infection with a $\mathrm{pH}$ independent activity. Again, SPL7013 has been demonstrated as a promising microbicide candidate in STIs.

\section{Influenza Virus Infection}

Influenza virus is a RNA virus that infects mainly vertebrates. There are 3 types of influenza: A, B, and C. Influenza $\mathrm{A}$ is the cause of all flu pandemics. This virus adheres to the target cells through the interaction of the main envelope glycoprotein: hemagglutinin (HA). HA recognizes sialic acid receptors on the host cell. It is known that monovalent sialic acid was able to prevent influenza A agglutination of chicken erythrocytes [102].

Whitesides et al., described in 1999 a pioneer work in the preparation of multivalent systems based on polyacrylamide functionalized with $\alpha$-sialoside groups (Fig. 22) [103].

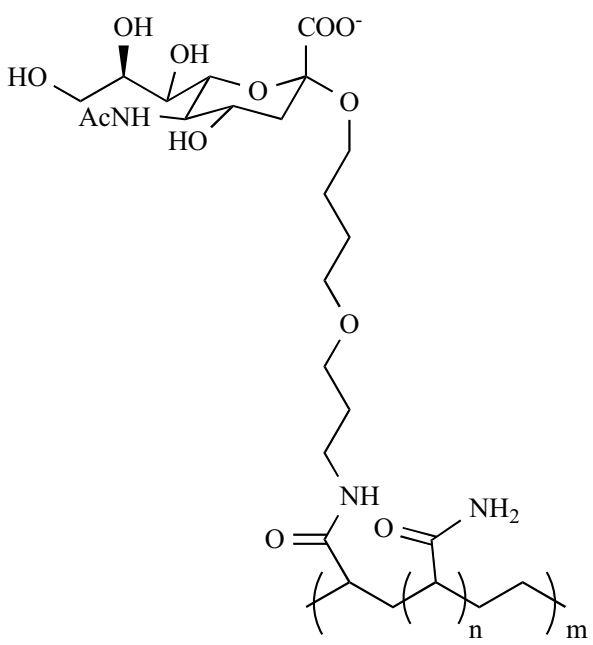

Fig. (22). $\alpha$-sialosyl functionalized polyacrylamide.

This glycopolymer strongly inhibited the agglutination of erythrocytes by influenza virus. Although this system is not a dendrimer (it is a glycopolymer), the work presented in this paper constitutes a milestone in the development of multivalent systems for influenza and has inspired later work of other authors. In fact, most of the work concerning dendrimeric structures development as anti-influenza virus infection was based on a multimeric presentation of sialic acid at the surface of these structures. Baker et al. developed systems based on PAMAM as dendritic core functionalized with sialic acid as described in the original papers and in a recent review [90].

\section{Food-and-Mouth Disease Virus (FMDV) Infection}

Food-and-mouth disease virus infects animals through the respiratory tract or skin abrasions and it is economically the most important disease in farm animals [104]. A very interesting approach to generate a vaccine against this infection has been described by Andreu et al. [105] A multivalent presentation of a lipidated cyclic peptide representing the main antigenic site of FMDV was preparing using a polylysine dendritic core (Fig. 23).

Guinea pig immunized with $500 \mu \mathrm{g}$ of a trivalent conjugate elicited antibodies with strong neutralizing activity.

\section{Ebola Virus Infection}

Ebola Virus along with Marburg virus constitute the Filoviridae family that is responsible of sporadic outbreaks of hemorrhagic fever in Africa characterized by a high death rate [106]. There is not currently any vaccine or specific treatment available for these dangerous agents and only sup-

Table 6. Inhibition Activities of SPL7013 in a HSV-1 and HSV-2 Infection Model

\begin{tabular}{|c|c|c|c|c|}
\hline Virus & \multicolumn{2}{|c|}{ HSV-1 } & \multicolumn{2}{c|}{ HSV-2 } \\
\hline \hline Treatment & PT & INF & PT & INF \\
\hline Mean EC $50(\mu \mathrm{g} / \mathrm{mL})$ & 2.0 & 6.1 & 0.5 & 3.8 \\
\hline
\end{tabular}




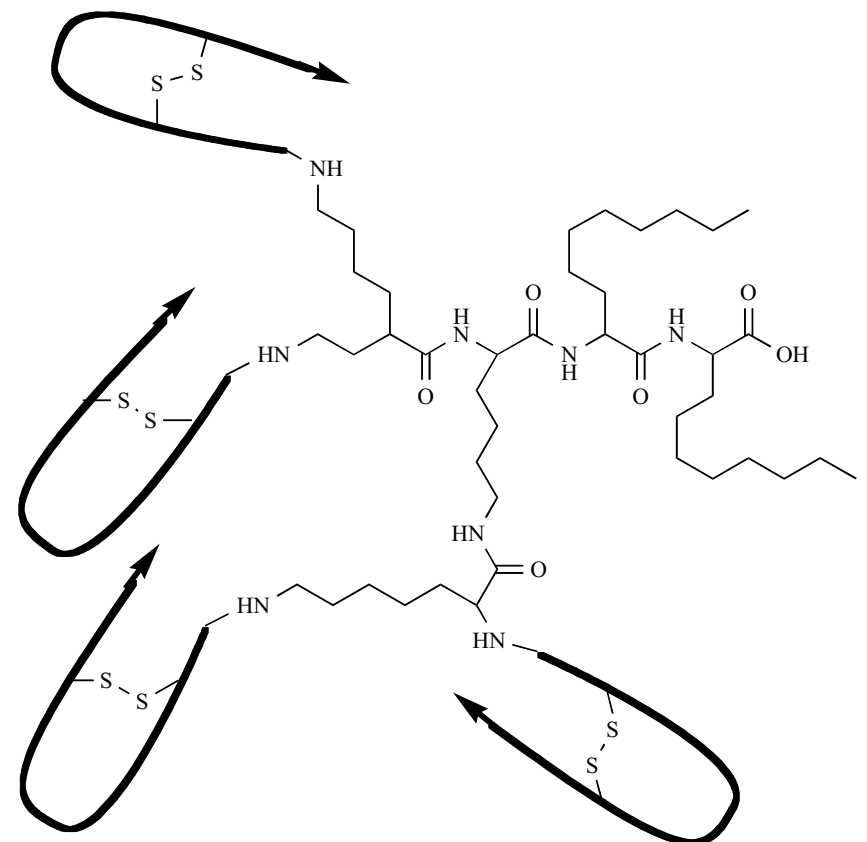

Fig. (23). Lipidated cyclic peptide functionalized polylysine dendrimer. portive measures can be provided for infected individuals. The envelope of Ebola virus consists of a trimer of a highly glycosilated glycoprotein that is recognized both by DCSIGN and DC-SIGNR/L-SIGN and it has been shown in vitro that the presence of these molecules can significantly increase the infectivity facilitating entry in cis and in trans, i.e. to susceptible neighbouring cells $[23,24]$. We have shown proof of principle that Ebola virus cellular infection enhancement by DC-SIGN can be blocked by a glycodendrimeric structure with CRDs specificity [107,108]. Our strategy was oriented to inhibit the entry of Ebola virus blocking the DC-SIGN lectin, a receptor that was described as one of the potential gate of entrance for this virus [23].

We have been involved during the last four years in developing glycodendritic structures based on the commercially available dendritic polymer Boltorn as multivalent core (Fig. 24) [107,108].

These dendritic structures could inhibit the infection process in a DC-SIGN dependent manner. Our preliminary results showed that at least the third generation of this dendritic polymer (BH30) functionalized with 32 mannoses at the surface presented a promising antiviral activity in a pseudotyped viral particles model of Ebola virus infection in cis and in trans with $\mathrm{IC}_{50}$ in the sub-micromolar range [108]. This is the first demonstration of potential application of a

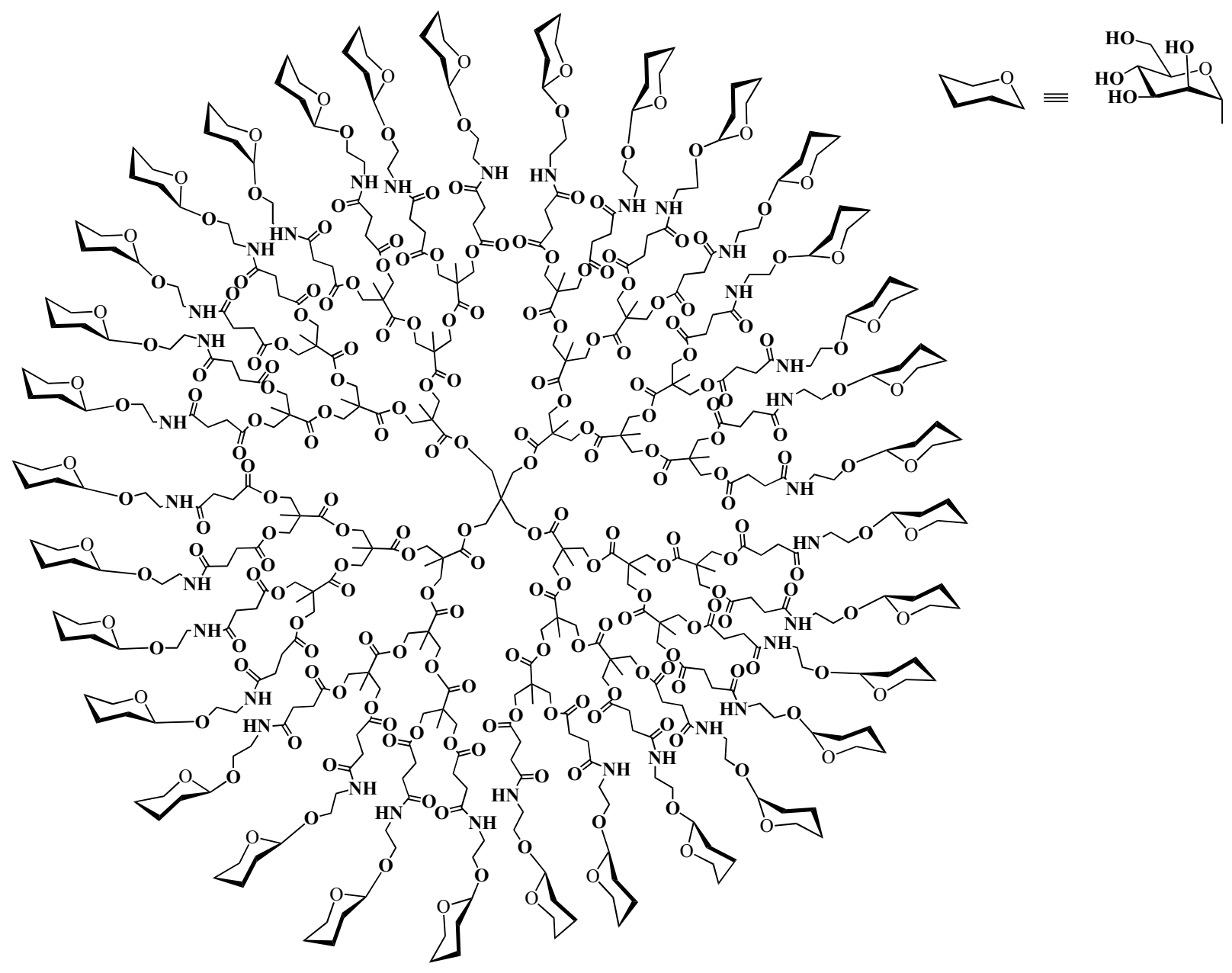

Fig. (24). Mannosyl functionalized dendritic polymer Boltorn 3G (BH30). 
dendrimer structure as a filovirus antiviral. These types of glycostructures were able to block the DC-SIGN receptor at the cell surface inhibiting the entrance of the pathogen and therefore, they could be used as microbicides.

\section{PERSPECTIVES}

Since the discovery and preparation of the first dendritic compound almost 3 decades ago, many attempts have been done by several groups to apply these dendritic structures in biomedicine. Most of the structures used as anti-infective agents are based on poly(amido amine) (PAMAM) and poly(propylene imine) (PPI) dendrimers. These are two well known structures and both of them commercially available up to generation 5 at least. Chemical manipulation of the dendritic surface (most of the time by the introduction of carbohydrates) are produced a large number of new structures with interesting antimicrobial properties as has been described along this review. This long road is close to be successful with the first dendritic compound in clinical Phase I showing promising antiviral properties. There is still a lot of work to do concerning the behaviour of these structures, their pharmacokinetics, etc. The chemistry of the dendrimer surface allows the introduction of diverse functional groups that control not only the physical-chemical properties of the dendrimers but also can modulate the activity of these compounds. Much work has been done respect to decrease the cytotoxicity that this type of entities can present. Changes of the functional groups at the surface or even the chemical structure of the core can be manipulated to achieve low toxicities, the first step required to reach a potential clinical application. We consider that dendrimers and dendritic polymers have to play a key role in the nanoscience field in next years. They are very flexible structures to be easily manipulated and modulated by chemists to achieve new properties and pursue future applications in biomedical science. In fact, the knowledge provided by all the research summarized above, establishes the bases for new accomplishments in the area of anti-infective agents with a broad spectrum of applications. Having a compound in clinical Phase I means a real step towards achieving the first milestone. We hope that in the next few decades, we could have derivatized dendritic compounds to be used as pharmaceuticals.

\section{ACKNOWLEDGEMENTS}

We would like to thank Instituto de Salud Carlos III (Spain Ministry of Health) projects PI030093 (J.R.) and PI030300 (R.D.) for financial support.

ABBREVIATIONS
$\begin{array}{ll}\text { cAMP } & =\text { Cyclic Adenosine Monophosphate } \\ \text { Cer } & =\text { Ceramide } \\ \text { CLR } & =\text { C-type Lectin Receptor } \\ \mathrm{CMV} & =\text { Cytomegalovirus } \\ \mathrm{CRD} & =\text { Carbohydrate Recognition Domain } \\ \mathrm{CTB} & =\text { Cholera Toxin B subunit } \\ \mathrm{DC} & =\text { Dendritic Cell }\end{array}$

\begin{tabular}{|c|c|c|}
\hline DC-SIGN & $=$ & $\begin{array}{l}\text { Dendritic Cell-Specific ICAM-3 Grabbing } \\
\text { Non-Integrin }\end{array}$ \\
\hline DC-SIGNR & $=$ & $\begin{array}{l}\text { Dendritic Cell-Specific ICAM-3 Grabbing } \\
\text { Non-Integrin Related }\end{array}$ \\
\hline ELISA & $=$ & Enzyme-Linked Immunosorbent Assay \\
\hline FDA & $=$ & Food and Drug Administration \\
\hline FMDV & $=$ & Food-and-Mouth Disease Virus \\
\hline Gal & $=$ & Galactose \\
\hline GalNAc & $=$ & N-Acetyl Galactosamine \\
\hline Glc & $=$ & Glucose \\
\hline GlcNAc & $=$ & N-Acetyl Glucosamine \\
\hline HA & $=$ & Hemagglutinin \\
\hline $\mathrm{HCV}$ & $=$ & Hepatitis C Virus \\
\hline HIV & $=$ & Human Immunodeficiency Virus \\
\hline HSV & $=$ & Herpes Simplex Virus \\
\hline ICAM-3 & $=$ & Intercellular Adhesion Molecule 3 \\
\hline Le & $=$ & Lewis \\
\hline LPS & $=$ & Lipopolysaccharide \\
\hline L-SIGN & $=$ & $\begin{array}{l}\text { Liver/lymph node-Specific ICAM-3 Grab- } \\
\text { bing Non-Integrin }\end{array}$ \\
\hline LT & $=$ & Heat Label Enterotoxin \\
\hline Man & $=$ & Mannose \\
\hline ManLAM & $=$ & Mannosylated Lipoarabinomannan \\
\hline MHC & $=$ & Major Histocompatibility Complex \\
\hline MIC & $=$ & Minimal Inhibitory Concentration \\
\hline NeuNAc & $=$ & N-Acetyl Neuraminic Acid \\
\hline NLR & $=$ & NOD-like Receptors \\
\hline PAMAM & $=$ & Poly(amido amine) \\
\hline PAMP & $=$ & Pathogen-associated Molecular Pattern \\
\hline PMBC & $=$ & Peripheral Mononuclear Blood Cell \\
\hline PPI & $=$ & Poly(propylene imine) \\
\hline $\operatorname{PrP}^{\mathrm{C}}$ & $=$ & Prion Protein normal form \\
\hline $\operatorname{PrP}^{\mathrm{S}}$ or $\operatorname{PrF}$ & $\mathrm{c}=$ & Prion Protein Scrapie form \\
\hline PRR & $=$ & Pattern-Recognition Receptor \\
\hline SARS & $=$ & Severe Acute Respiratory Syndrome \\
\hline SHIV & $=$ & Simian Human Immunodeficiency Virus \\
\hline SLT & $=$ & Shiga-Like Toxin \\
\hline STD & $=$ & Sexual Transmitted Disease \\
\hline STI & $=$ & Sexual Transmitted Infection \\
\hline Stx & $=$ & Shiga Toxin \\
\hline TLR & $=$ & Toll-Like Receptor \\
\hline $\operatorname{Trp}$ & $=$ & Tryptophan \\
\hline TSI & $=$ & Toxic Shock Syndrome \\
\hline
\end{tabular}




\section{REFERENCES}

[1] Buhleier, E.; Wehner, W.; Vögtle, F. Synthesis 1978, 155.

[2] Matthews, O. A.; Shipway, A. N.; Stoddart, J. F. Prog. Polymer Sci. 1998, 23, 1.

[3] Fréchet, J. M. J.; Tomalia, D. A. Dendrimers and other dendritic polymers; John Wiley \& Sons: Chichester, 2001.

[4] Newkome, G. R.; Moorefield, C. N.; Vögtle, F. Dendrimers and Dendrons; Wiley-VCH: Weinheim, 2001.

[5] Bosman, A. W.; Janssen, H. M.; Meijer, E. W. Chem. Rev. 1999, 99, 1665.

[6] Bezouska, K. J. Biotechnol. 2002, 90, 269.

[7] Stiriba, S. E.; Frey, H.; Haag, R. Angew. Chem. Int. Ed. 2002, 41, 1329.

[8] Cloninger, M. J. Curr. Opin. Chem. Biol. 2002, 6, 742.

[9] Boas, U.; Heegaard, P. M. H. Chem. Soc. Rev. 2004, 33, 43

[10] Svenson, S.; Tomalia, D. A. Adv. Drug Deliv. Rev. 2005, 57, 2106.

[11] Lee, C. C.; MacKay, J. A.; Fréchet, J. M.; Szoka, F. C. Nat. Biotechnol. 2005, 23, 1517 .

[12] Haag, R.; Kratz, F. Angew. Chem. Int. Ed. 2006, 45, 1198.

[13] Janeway, C. A., Jr.; Medzhitov, R. Annu. Rev. Immunol. 2002, 20, 197.

[14] Beutler, B.; Jiang, Z.; Georgel, P.; Crozat, K.; Croker, B.; Rutschmann, S.; Du, X.; Hoebe, K. Annu. Rev. Immunol. 2006, 24, 353.

[15] Inohara; Chamaillard; McDonald, C.; Nunez, G. Annu. Rev. Biochem. 2005, 74, 355.

[16] Figdor, C. G.; van Kooyk, Y.; Adema, G. J. Nat. Rev. Immunol. 2002, 2, 77

[17] Robinson, M. J.; Sancho, D.; Slack, E. C.; Leibunggut-Landmann, S.; Sousa, C. R. Nat. Immunol. 2006, 7, 1258.

[18] Turville, S.; Wilkinson, J.; Cameron, P.; Dable, J.; Cunningham, A. L. J. Leukoc. Biol. 2003, 74, 710 .

[19] Allavena, P.; Chieppa, M.; Monti, P.; Piemonti, L. Crit. Rev. Immunol. 2004, 24, 179

[20] Geijtenbeek, T. B.; Kwon, D. S.; Torensma, R.; van Vliet, S. J.; van Duijnhoven, G. C.; Middel, J.; Cornelissen, I. L.; Nottet, H. S.; Kewalramani, V. N.; Littman, D. R.; Figdor, C. G.; van Kooyk, Y. Cell 2000, 100, 587

[21] Halary, F.; Amara, A.; Lortat-Jacob, H.; Messerle, M.; Delaunay, T.; Houles, C.; Fieschi, F.; Arenzana-Seisdedos, F.; Moreau, J. F.; chanet-Merville, J. Immunity 2002, 17, 653

[22] Geijtenbeek, T. B.; van Vliet, S. J.; Koppel, E. A.; SanchezHernandez, M.; Vandenbroucke-Grauls, C. M.; Appelmelk, B.; van Kooyk, Y. J. Exp. Med. 2003, 197, 7.

[23] Alvarez, C. P.; Lasala, F.; Carrillo, J.; Muniz, O.; Corbi, A. L.; Delgado, R. J. Virol. 2002, 76, 6841.

[24] Simmons, G.; Reeves, J. D.; Grogan, C. C.; Vandenberghe, L. H.; Baribaud, F.; Whitbeck, J. C.; Burke, E.; Buchmeier, M. J.; Soilleux, E. J.; Riley, J. L.; Doms, R. W.; Bates, P.; Pohlmann, S. Virology $\mathbf{2 0 0 3}, 305,115$.

[25] Lozach, P. Y.; Lortat-Jacob, H.; de Lacroix de, L. A.; Staropoli, I.; Foung, S.; Amara, A.; Houles, C.; Fieschi, F.; Schwartz, O.; Virelizier, J. L.; Arenzana-Seisdedos, F.; Altmeyer, R. J. Biol. Chem. 2003, 278, 20358.

[26] Brown, G. D.; Taylor, P. R.; Reid, D. M.; Willment, J. A.; Williams, D. L.; Martinez-Pomares, L.; Wong, S. Y.; Gordon, S. J. Exp. Med. 2002, 196, 407.

[27] McGreal, E. P.; Rosas, M.; Brown, G. D.; Zamze, S.; Wong, S. Y.; Gordon, S.; Martinez-Pomares, L.; Taylor, P. R. Glycobiology 2006, 16,422

[28] Turville, S. G.; Cameron, P. U.; Handley, A.; Lin, G.; Pohlmann, S.; Doms, R. W.; Cunningham, A. L. Nat. Immunol. 2002, 3, 975.

[29] Takada, A.; Fujioka, K.; Tsuiji, M.; Morikawa, A.; Higashi, N.; Ebihara, H.; Kobasa, D.; Feldmann, H.; Irimura, T.; Kawaoka, Y. J. Virol. 2004, 78, 2943.

[30] Gramberg, T.; Hofmann, H.; Moller, P.; Lalor, P. F.; Marzi, A.; Geier, M.; Krumbiegel, M.; Winkler, T.; Kirchhoff, F.; Adams, D. H.; Becker, S.; Munch, J.; Pohlmann, S. Virology 2005, 340, 224

[31] Liu, W.; Tang, L.; Zhang, G.; Wei, H.; Cui, Y.; Guo, L.; Gou, Z.; Chen, X.; Jiang, D.; Zhu, Y.; Kang, G.; He, F. J. Biol. Chem. 2004, 279, 18748.

[32] Geijtenbeek, T. B.; Torensma, R.; van Vliet, S. J.; van Duijnhoven, G. C.; Adema, G. J.; van Kooyk, Y.; Figdor, C. G. Cell 2000, 100, 575 .

[33] Curtis, B. M.; Scharnowske, S.; Watson, A. J. Proc. Natl. Acad. Sci. U.S.A 1992, 89, 8356.
[34] Feinberg, H.; Mitchell, D. A.; Drickamer, K.; Weis, W. I. Science 2001, 294, 2163.

[35] Bashirova, A. A.; Geijtenbeek, T. B.; van Duijnhoven, G. C.; van Vliet, S. J.; Eilering, J. B.; Martin, M. P.; Wu, L.; Martin, T. D.; Viebig, N.; Knolle, P. A.; Kewalramani, V. N.; van Kooyk, Y.; Carrington, M. J. Exp. Med. 2001, 193, 671

[36] Gramberg, T.; Caminschi, I.; Wegele, A.; Hofmann, H.; Pohlmann, S. Virology 2006, 345, 482.

[37] Sakuntabhai, A.; Turbpaiboon, C.; Casademont, I.; Chuansumrit, A.; Lowhnoo, T.; Kajaste-Rudnitski, A.; Kalayanarooj, S. M.; Tangnararatchakit, K.; Tangthawornchaikul, N.; Vasanawathana, S.; Chaiyaratana, W.; Yenchitsomanus, P. T.; Suriyaphol, P.; Avirutnan, P.; Chokephaibulkit, K.; Matsuda, F.; Yoksan, S.; Jacob, Y.; Lathrop, G. M.; Malasit, P.; Despres, P.; Julier, C. Nat. Genet 2005, 37, 507.

[38] Gramberg, T.; Zhu, T.; Chaipan, C.; Marzi, A.; Liu, H.; Wegele, A.; Andrus, T.; Hofmann, H.; Pohlmann, S. Virology 2006, 347, 354.

[39] Martin, M. P.; Lederman, M. M.; Hutcheson, H. B.; Goedert, J. J.; Nelson, G. W.; van, K. Y.; Detels, R.; Buchbinder, S.; Hoots, K.; Vlahov, D.; O'Brien, S. J.; Carrington, M. J. Virol. 2004, 78, 14053.

[40] Liu, H.; Hwangbo, Y.; Holte, S.; Lee, J.; Wang, C.; Kaupp, N.; Zhu, H.; Celum, C.; Corey, L.; McElrath, M. J.; Zhu, T. J. Infect. Dis. 2004, 190, 1055.

[41] Den Brok, M. H.; Nierkens, S.; Figdor, C. G.; Ruers, T. J.; Adema, G. J. Expert Rev. Vaccines 2005, 4, 699.

[42] Engering, A.; Geijtenbeek, T. B.; van Vliet, S. J.; Wijers, M.; van, L. E.; Demaurex, N.; Lanzavecchia, A.; Fransen, J.; Figdor, C. G.; Piguet, V.; van Kooyk, Y. J. Immunol. 2002, 168, 2118.

[43] Simon, V.; Ho, D. D. Nat. Rev. Microbiol 2003, 1, 181

[44] Dakappagari, N.; Maruyama, T.; Renshaw, M.; Tacken, P.; Figdor, C.; Torensma, R.; Wild, M. A.; Wu, D.; Bowdish, K.; KretzRommel, A. J. Immunol. 2006, 176, 426.

[45] Paddle, B. M. J. Appl. Toxicol. 2003, 23, 139.

[46] Thompson, J. P.; Schengrund, C. L. Glycoconjugate J. 1997, 14 837.

[47] Thompson, J. P.; Schengrund, C. L. Biochem. Pharm. 1998, 56, 591.

[48] Vrasidas, I.; de Mol, N. J.; Liskamp, R. M. J.; Pieters, R. J. Eur. J. Org. Chem. 2001, 4685.

[49] Arosio, D.; Vrasidas, I.; Valentini, P.; Liskamp, R. M. J.; Pieters, R. J.; Bernardi, A. Org. Biomol. Chem. 2004, 2, 2113.

[50] Kitov, P. I.; Sadowska, J. M.; Mulvey, G.; Armstrong, G. D.; Ling, H.; Pannu, N. S.; Read, R. J.; Bundle, D. R. Nature 2000, 403, 669 Mulvey, G. L.; Marcato, P.; Kitov, P. I.; Sadowska, J.; Bundle, D. R.; Armstrong, G. D. J. Infect. Dis. 2003, 187, 640.

[52] Nishikawa, K.; Matsuoka, K.; Kita, E.; Okabe, N.; Mizuguchi, M.; Hino, K.; Miyazawa, S.; Yamasaki, C.; Aoki, J.; Takashima, S.; Yamakawa, Y.; Nishijima, M.; Terunuma, D.; Kuzuhara, H.; Natori, Y. Proc. Natl. Acad. Sci. U.S.A 2002, 99, 7669.

[53] Nishikawa, K.; Matsuoka, K.; Watanabe, M.; Igai, K.; Hino, K.; Hatano, K.; Yamada, A.; Abe, N.; Terunuma, D.; Kuzuhara, H.; Natori, Y. J. Infect. Dis. 2005, 191, 2097.

[54] Yamada, A.; Hatano, K.; Matsuoka, K.; Koyama, T.; Esumi, Y.; Koshino, H.; Hino, K.; Nishikawa, K.; Natori, Y.; Terunuma, D. Tetrahedron 2006, 62, 5074

[55] Nataro, J. P.; Kaper, J. B. Clin. Microbiol. Rev. 1998, 11, 142

[56] Rietschel, E. T.; Kirikae, T.; Schade, F. U.; Mamat, U.; Schmidt, G.; Loppnow, H.; Ulmer, A. J.; Zahringer, U.; Seydel, U.; Dipadova, F.; Schreier, M.; Brade, H. FASEB J. 1994, 8, 217.

[57] David, S. A.; Silverstein, R.; Amura, C. R.; Kielian, T.; Morrison, D. C. Antimicrob. Agents Chemother. 1999, 43, 912.

[58] Cromer, J. R.; Wood, S. J.; Miller, K. A.; Nguyen, T.; David, S. A Bioorg. Med. Chem. Lett. 2005, 15, 1295.

[59] Connell, H.; Agace, W.; Klemm, P.; Schembri, M.; Marild, S.; Svanborg, C. Proc. Natl. Acad. Sci. U.S.A 1996, 93, 9827.

[60] Kotter, S.; Krallmann-Wenzel, U.; Ehlers, S.; Lindhorst, T. K. J. Chem. Soc. Perkin Trans. 1 1998, 2193.

[61] Lindhorst, T. K.; Dubber, M.; Krallmann-Wenzel, U.; Ehlers, S. Eur. J. Org. Chem. 2000, 2027.

[62] Lindhorst, T. K.; Kotter, S.; Krallmann-Wenzel, U.; Ehlers, S. J. Chem. Soc. Perkin Trans. 1 2001, 823.

[63] Lindhorst, T. K.; Kieburg, C.; Krallmann-Wenzel, U. Glycoconjug. J. 1998, 15, 605 . 
[64] Nagahori, N.; Lee, R. T.; Nishimura, S.; Page, D.; Roy, R.; Lee, Y. C. ChemBioChem 2002, 3, 836 .

[65] Autar, R.; Khan, A. S.; Schad, M.; Hacker, J.; Liskamp, R. M. J.; Pieters, R. J. ChemBioChem 2003, 4, 1317.

[66] Appeldoorn, C. C. M.; Joosten, J. A. F.; El Maate, F. A.; Dobrindt, U.; Hacker, J.; Liskamp, R. M. J.; Khan, A. S.; Pieters, R. J. Tetrahedron-Asymm. 2005, 16, 361.

[67] Ghosh, S.; Banthia, A. K. J. Biomed. Mat. Res. Part A 2004, 71A, 1 .

[68] Janiszewska, J.; Urbanczyk-Lipkowska, Z. Acta Biochim. Pol. 2006, 53, 77.

[69] Janiszewska, J.; Swieton, J.; Lipkowski, A. W.; UrbanczykLipkowska, Z. Bioorg. Med. Chem. Lett. 2003, 13, 3711.

[70] Chen, C. Z. S.; Beck-Tan, N. C.; Dhurjati, P.; van Dyk, T. K.; LaRossa, R. A.; Cooper, S. L. Biomacromolecules 2000, 1, 473.

[71] Staats, J. J.; Feder, I.; Okwumabua, O.; Chengappa, M. M. Vet. Res. Commun. 1997, 21, 381.

[72] Gottschalk, M.; Segura, M. Vet. Microbiol. 2000, 76, 259.

[73] Tikkanen, K.; Haataja, S.; Francoisgerard, C.; Finne, J. J. Biol. Chem. 1995, 270, 28874.

[74] Hansen, H. C.; Haataja, S.; Finne, J.; Magnusson, G. J. Am. Chem. Soc. 1997, 119, 6974.

[75] Joosten, J. A. F.; Loimaranta, V.; Appeldoorn, C. C. M.; Haataja, S.; El Maate, F. A.; Liskamp, R. M. J.; Finne, J.; Pieters, R. J. J. Med. Chem. 2004, 47, 6499 .

[76] Lowy, F. D. N. Engl. J. Med. 1998, 339, 520.

[77] Chen, C. Z. S.; Beck-Tan, N. C.; Dhurjati, P.; van Dyk, T. K.; LaRossa, R. A.; Cooper, S. L. Biomacromolecules 2000, 1, 473.

[78] Cisar, J. O.; Kolenbrander, P. E.; McIntire, F. C. Infect. Immun. 1979, 24, 742 .

[79] Rendle, P. M.; Seger, A.; Rodrigues, J.; Oldham, N. J.; Bott, R. R.; Jones, J. B.; Cowan, M. M.; Davis, B. G. J. Am. Chem. Soc. 2004, 126,4750

[80] Rozell, B.; Ljungdahl, P. O.; Martinez, P. Curr. Drug Targets 2006, $7,483$.

[81] Filler, S. G. Curr. Opin. Microbiol. 2006, 9, 333.

[82] Prusiner, S. B. Science 1982, 216, 136.

[83] Supattapone, S.; Nguyen, H. O. B.; Cohen, F. E.; Prusiner, S. B.; Scott, M. R. Proc. Natl. Acad. Sci. U.S.A 1999, 96, 14529.

[84] Supattapone, S.; Wille, H.; Uyechi, L.; Safar, J.; Tremblay, P.; Szoka, F. C.; Cohen, F. E.; Prusiner, S. B.; Scott, M. R. J. Virol. 2001, 75, 3453.

[85] Klajnert, B.; Cladera, J.; Bryszewska, M. Biomacromolecules 2006, 7,2186

[86] Klajnert, B.; Cortijo-Arellano, M.; Cladera, J.; Bryszewska, M. Biochem. Biophys. Res. Commun. 2006, 345, 21.
[87] Klajnert, B.; Cortijo-Arellano, M.; Bryszewska, M.; Cladera, J. Biochem. Biophys. Res. Commun. 2006, 339, 577.

[88] Heegaard, P. M. H.; Pedersen, H. G.; Flink, J.; Boas, U. Febs Lett. 2004, 577, 127.

[89] Solassol, J.; Crozet, C.; Perrier, V.; Leclaire, J.; Beranger, F.; Caminade, A. M.; Meunier, B.; Dormont, D.; Majoral, J. P.; Lehmann, S. J. Gen. Virol. 2004, 85, 1791.

[90] Rosa, B. A.; Schengrund, C. L. Curr. Drug Targets Infect. Disord. $\mathbf{2 0 0 5}, 5,247$.

[91] Stone, A. Nat. Rev. Drug Discov. 2002, 1, 977.

[92] Shattock, R. J.; Moore, J. P. Nat. Rev. Microbiol. 2003, 1, 25.

[93] Dezzutti, C. S.; James, V. N.; Ramos, A.; Sullivan, S. T.; Siddig, A.; Bush, T. J.; Grohskopf, L. A.; Paxton, L.; Subbarao, S.; Hart, C. E. Antimicrob. Agents Chemother. 2004, 48, 3834

[94] Patton, D. L.; Cosgrove Sweeney, Y. T.; McCarthy, T. D.; Hillier, S. L. Antimicrob. Agents Chemother. 2006, 50, 1696.

[95] Abner, S. R.; Guenthner, P. C.; Guarner, J.; Hancock, K. A.; Cummins, J. E., Jr.; Fink, A.; Gilmore, G. T.; Staley, C.; Ward, A.; Ali, O.; Binderow, S.; Cohen, S.; Grohskopf, L. A.; Paxton, L.; Hart, C. E.; Dezzutti, C. S. J. Infect. Dis. 2005, 192, 1545.

[96] Jiang, Y. H.; Emau, P.; Cairns, J. S.; Flanary, L.; Morton, W. R.; McCarthy, T. D.; Tsai, C. C. Aids Res. Hum. Retroviruses 2005 21, 207.

[97] McCarthy, T. D.; Karellas, P.; Henderson, S. A.; Giannis, M.; O'Keefe, D. F.; Heery, G.; Paull, J. R.; Matthews, B. R.; Holan, G. Mol. Pharm. 2005, 2, 312 .

[98] Harouse, J. M.; Bhat, S.; Spitalnik, S. L.; Laughlin, M.; Stefano, K.; Silberberg, D. H.; Gonzalez-Scarano, F. Science 1991, 253, 320 .

[99] Blanzat, M.; Turrin, C. O.; Aubertin, A. M.; Couturier-Vidal, C.; Caminade, A. M.; Majoral, J. P.; Rico-Lattes, I.; Lattes, A. ChemBioChem 2005, 6, 2207.

[100] Kleymann, G. Expert Opin. Inv. Drugs 2003, 12, 165.

[101] Gong, E.; Matthews, B.; McCarthy, T.; Chu, J. H.; Holan, G.; Raff, J.; Sacks, S. Antiviral Res. 2005, 68, 139.

[102] Weis, W.; Brown, J. H.; Cusack, S.; Paulson, J. C.; Skehel, J. J.; Wiley, D. C. Nature 1988, 333, 426

[103] Lees, W. J.; Spaltenstein, A.; Kingery-Wood, J. E.; Whitesides, G. M. J. Med. Chem. 1994, 37, 3419.

[104] Sobrino, F.; Domingo, E. EMBO Rep. 2001, 2, 459.

[105] de Oliveira, E.; Villen, J.; Giralt, E.; Andreu, D. Bioconjug. Chem. 2003, 14, 144 .

[106] Peters, C. J.; LeDuc, J. W. J. Infect. Dis. 1999, 179 Suppl 1, ix.

[107] Rojo, J.; Delgado, R. J. Antimicrob. Chemother. 2004, 54, 579.

[108] Lasala, F.; Arce, E.; Otero, J. R.; Rojo, J.; Delgado, R. Antimicrob. Agents Chemother. 2003, 47, 3970. 